Portland State University

PDXScholar

$12-9-2021$

\title{
Impacts of Nontraditional Admissions Criteria on the Admittance and Retention of Academically At-Risk Student Populations
}

Kristen Marie Winter

Portland State University

Follow this and additional works at: https://pdxscholar.library.pdx.edu/open_access_etds

Part of the Educational Leadership Commons, and the Secondary Education Commons Let us know how access to this document benefits you.

\section{Recommended Citation}

Winter, Kristen Marie, "Impacts of Nontraditional Admissions Criteria on the Admittance and Retention of Academically At-Risk Student Populations" (2021). Dissertations and Theses. Paper 5864.

https://doi.org/10.15760/etd.7735

This Dissertation is brought to you for free and open access. It has been accepted for inclusion in Dissertations and Theses by an authorized administrator of PDXScholar. Please contact us if we can make this document more accessible: pdxscholar@pdx.edu. 
Impacts of Nontraditional Admissions Criteria on the Admittance and Retention of Academically At-Risk Student Populations

by

Kristen Marie Winter

A dissertation submitted in partial fulfillment of the requirements for the degree of

Doctor of Education

in

Educational Leadership: Postsecondary Education

Dissertation Committee:

Candyce Reynolds, Chair

Moti Hara

Thomas Luckett

Larry Roper

Portland State University

2021 
(C) 2021 Kristen Marie Winter 


\begin{abstract}
The purpose of this study is to examine impacts of non-cognitive measures in the college admissions process on the retention of academically at-risk student populations. Increasing access to higher education is of benefit to individual and society as a whole. Traditional college admissions practices use standardized testing and GPA, which have been criticized for not being the best sole predictor for college preparedness. The use of non-cognitive measures may increase diversity and equity within the college admissions process.
\end{abstract}

This study considers students admitted to college through an extended admissions process who have completed short essays addressing non-cognitive measures. These students would be seen as "academically at-risk" due to their lower high school GPA, lower test scores, and/or missing preparatory requirements. This study will consider if the probability of being admitted to college changes based on non-cognitive scores using a quantitative research process.

The researcher used descriptive statistics, group means analysis, linear and logistic regression to examine if the use of non-traditional admissions procedures has impact on admission to college and first-to-second year retention of freshman students. After analyzing underlying demographic characteristics, the combination of standardized test scores, high school GPA, ACT, gender and race were determined to be reliable predictors of first to second-year retention. When used as a sole variable the Insight 
Resume does not have predictive value for first to second year retention, but when combined with other variables the predictive value for first to second year retention can increase. 


\section{Acknowledgements}

Words cannot describe the gratitude I have in all those who have helped me come this far in my educational journey. I would like to acknowledge and thank my advisor, Dr. Candyce Reynolds, for her undying patience and belief in me. Additional thank you to my committee for sticking with me during this long process. Tom, Moti and Larry - I appreciate all of your time and energy. Tom - your initial edits were wonderful. Moti you started my interest in and appreciation for statistics. Larry - you raised me up properly in the world of Student Affairs and have been an inspiring mentor during my career.

Many thanks to Dr. Michael Shin, professor of Geography at UCLA (also known as my brother-in-law), for his assistance in logistical regression data crunching to get my head back in the game after a long time away from stats. Additional thanks to Dr. Chris Meiers for being my stats guru, cheerleader, go-to editor, and friend.

Thank you to my supervisors over the years who have encouraged me to complete what I started. And to my current colleagues who made sure I finished.

I would also like to acknowledge my family (Mom, Dad, Nancy, Jen, Tony and Lib) for always believing I could do hard things. And to my sweetheart, Christian Olson, for his magical blend of challenge and support. Thank you to Annika and Zoe for cheering me on and checking on my progress during the final stages of completing this dissertation ("how many pages is your paper?"). All of you stuck with me through the 
many emotions, stops and restarts, that a decade of working towards a doctorate can bring.

You never know what you can accomplish until you push yourself - and I really had to push myself to achieve this level of education. Ultimately, this research and my work within it is dedicated to students. I believe in the powerful transformation that education can bring. It is my hope that this research helps even just one person be admitted and be retained, so that they can push themselves to achieve their own goals, dreams and aspirations. 


\section{Table of Contents}

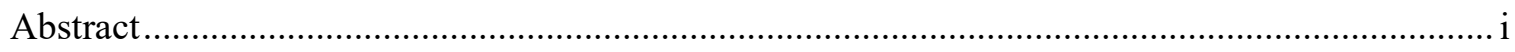

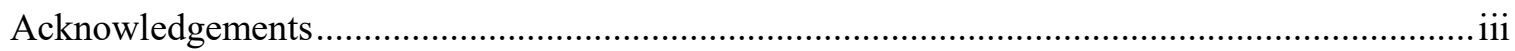

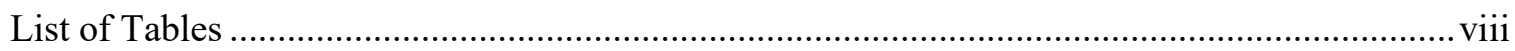

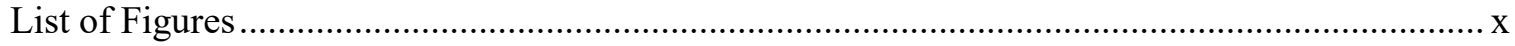

Chapter One: Impact of nontraditional admissions criteria on the admittance and retention

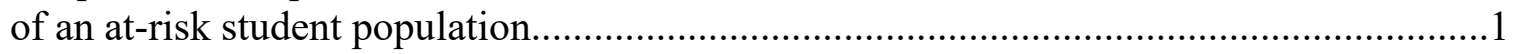

Significance of a Diverse Student Population............................................................... 3

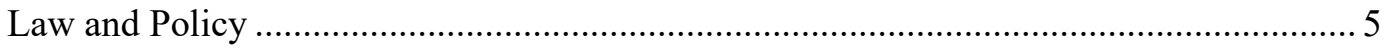

Evaluating Student for Admission ......................................................................... 7

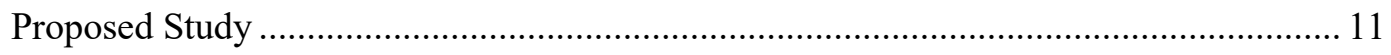

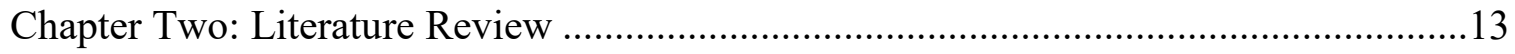

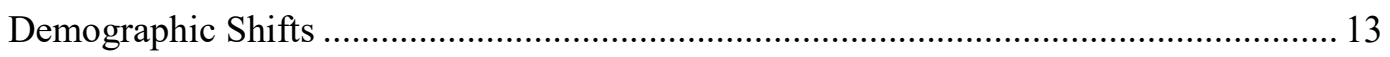

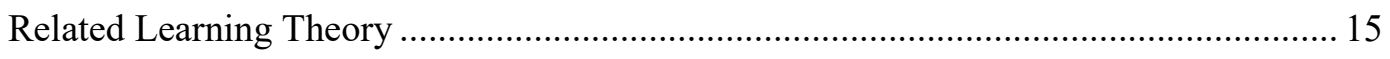

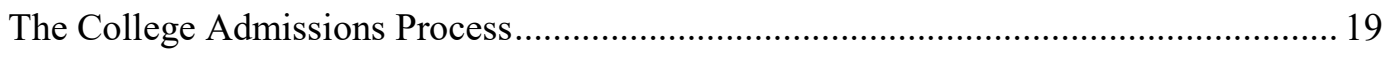

Law, legislation, policy, and issues of relevance..................................................... 22

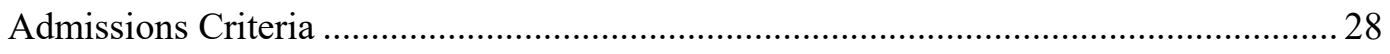

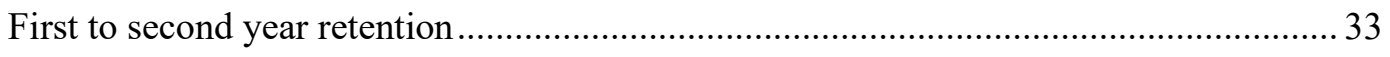

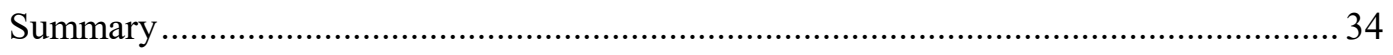

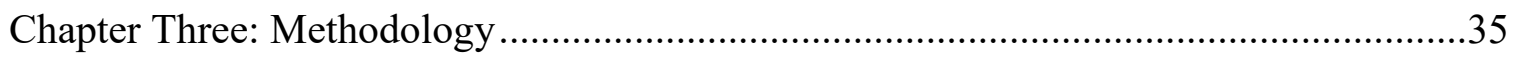

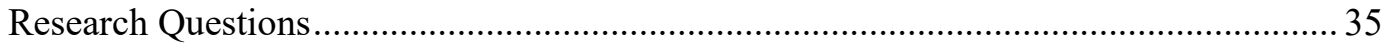

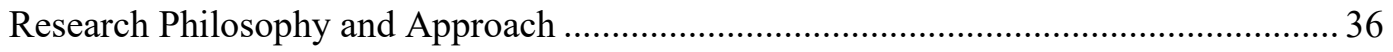

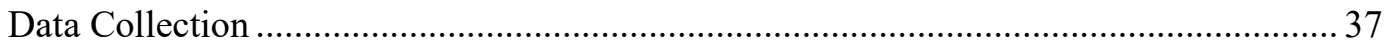




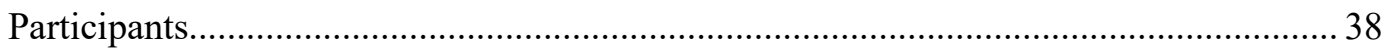

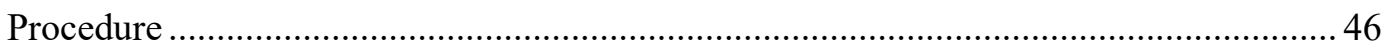

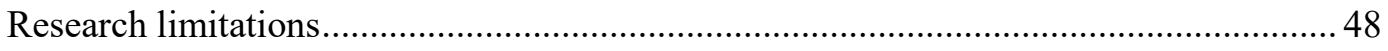

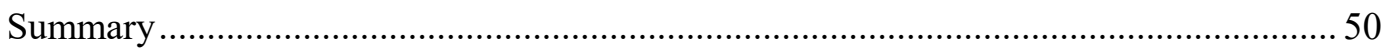

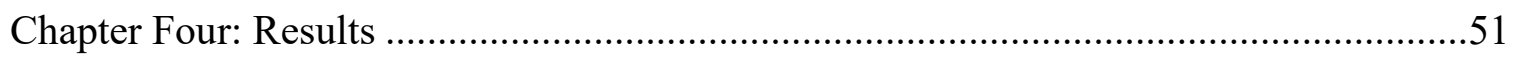

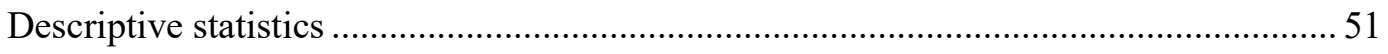

Research Question 1: Underlying Demographic Variables and Admissions Type Analysis

Research Question 2: High School GPA, Test Scores, and Admissions Type Analysis .. 56

Research Question 3: Demographic Characteristics, High School GPA Analysis, and

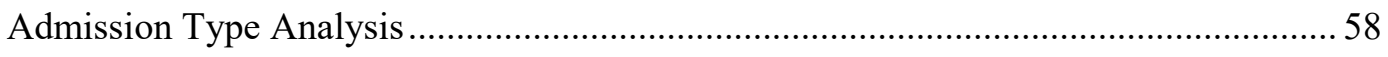

Research Question 4: Demographic Variables, Admission Type and First-to-Second First

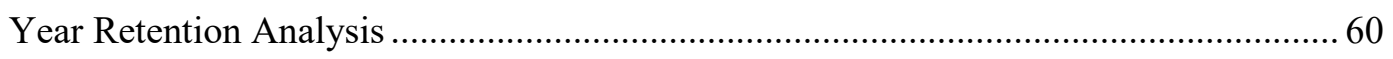

Research Question 5: Analysis of High School GPA, Admissions Test Scores, and IR

Scores for Admitted Students in Predicting First-to-Second Year Retention.................... 63

Research Question 6: Analysis of College Admission Test Scores, Demographic

Characteristics, High School GPA, and IR Scores in Predicting First-to-Second Year

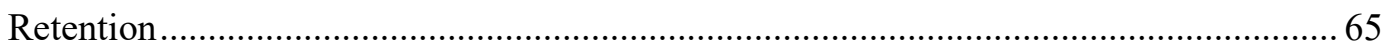

Research Question 7: Analysis of Predictive Validity in First-to-Second Year Retention

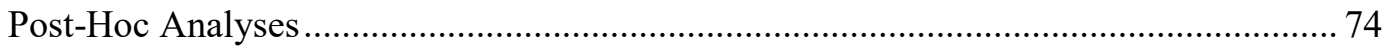

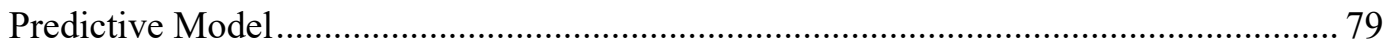

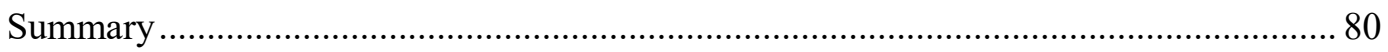




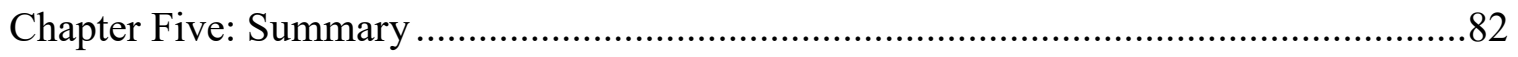

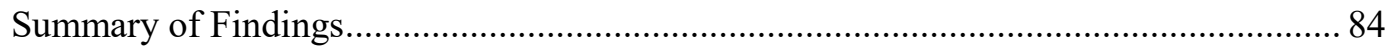

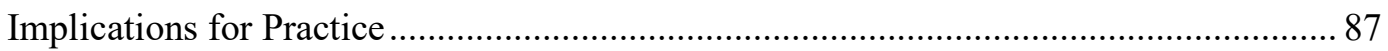

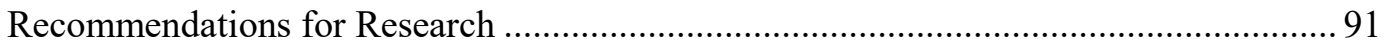

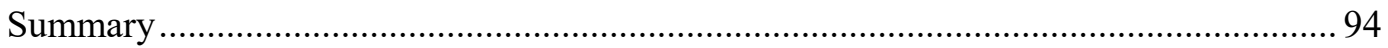

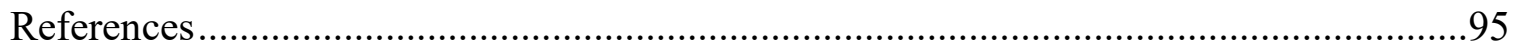

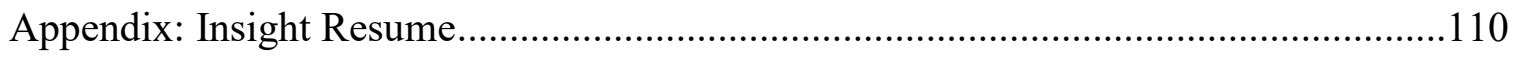

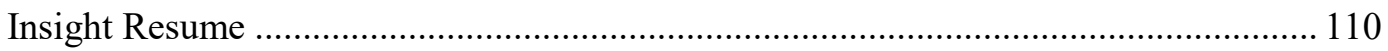




\section{List of Tables}

Table 1: Frequency Distributions of the 2016-2018 Freshman Class $(n=12,368)$

Distributions of 2016-2018 Freshman Class $(n=12,368)$.

Table 2: Descriptive Statistics for Test Score and High School GPA..................42

Table 3 First-to-Second Year Retention Rate ......................................................45

Table 4: Participants Break-Down by Admission Type ......................................52

Table 5: Participant Break-Down by Retention Status ........................................53

Table 6: Regression Analysis Summary for Underlying Demographic Variables

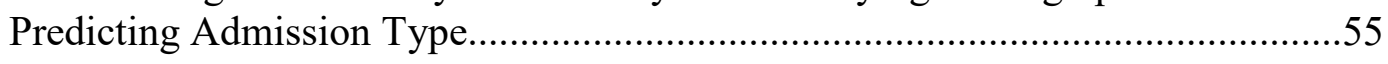

Table 7: Regression Analysis Summary for Demographics Predicting Admission

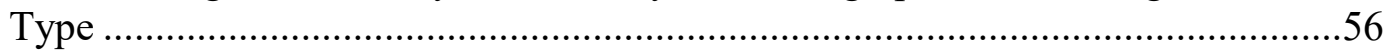

Table 8: Regression Analysis Summary for Test Scores and High School GPA

Predicting Admission Type............................................................................57

Table 9: Regression Analysis Summary for High School GPA Predicting

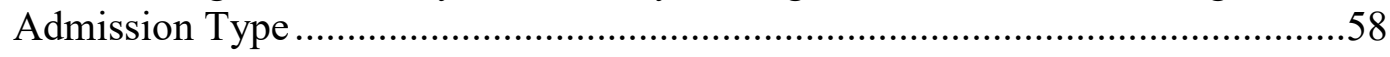

Table 10: Regression Analysis Summary for Demographics and High School

GPA Predicting Admission Type....

Table 11: Regression Analysis Summary for Demographics, Admission Type in

Predicting First-to-Second Year Retention....

Table 12: Multiple Linear Regression Analysis for Demographics Predicting

First-to-Second Year Retention ..................................................................63

Table 13: Regression Analysis Summary for High School GPA, Test Scores, and IR Scores to Predict First-to-Second Year Retention

Table 14: Multiple Linear Regression for High School GPA and SAT Combine in

Predicting First-to-Second Year Retention 65

Table 15: Regression Analysis Summary for SAT Combined Test Scores, Demographic Characteristics, IR Scores, Admission Type and High School GPA to Predict First-to-Second Year Retention.

Table 16: Regression Analysis Summary for Insight Resume Score to Predict First-to-Second Year Retention 
Table 17: Linear Regression Analysis Summary for SAT Combines Test Scores, Demographic Characteristics, IR Scores and High School GPA to Predict First-to-

Second Year Retention .69

Table 18: Linear Regression Analysis Summary for SAT Combines Test Scores, Demographic Characteristics and High School GPA to Predict First-to-Second Year Retention

Table 19: Logistics Regression to Demonstrate Effects of Demographics, Admission Type, IR Score, High School GPA and SAT Combined on First to Second Year Retention

Table 20: Logistic Regression Classification Table for First-to-Second Year

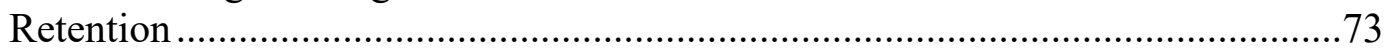

Table 21: Regression to Predict Impact of Admissions Type on First to Second Year Retention

Table 22: Pearson Correlation Coefficients for High School GPA, Standardized Test Scores, and IR Total Scores ................................................................... 76

Table 23: Demographic Summary of IR Test Scores by Race ...........................79

Table 24: Linear Regression for Demographic of Race and First to Second Year

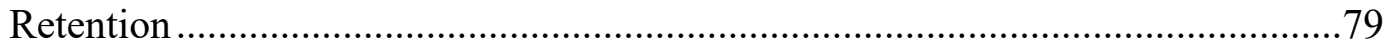




\section{List of Figures}

Figure 1: High School GPA Histogram ..................................................... 42

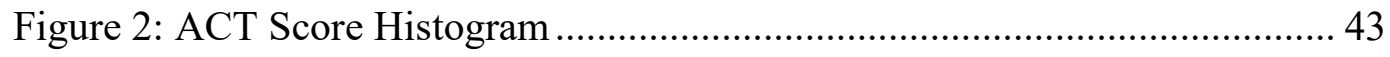

Figure 3: SAT Score Histogram ............................................................... 44

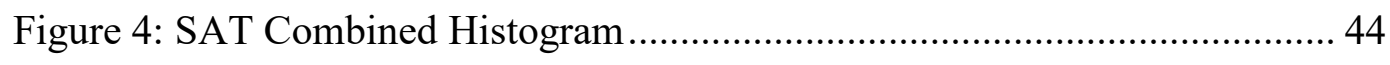

Figure 5: IR Total Score Histogram....................................................... 45

Figure 6: Combined SAT Score and High School GPA Scatter Plot .................. 76

Figure 7: IR Total Score and High School GPA Scatter Plot ............................. 77

Figure 8: Combined SAT Score and IR Total Score Scatter Plot....................... 77

Figure 9: ACT Score and IR Total Score Scatter Plot .................................... 78 


\section{Chapter One: Impact of nontraditional admissions criteria on the admittance and retention of an at-risk student population}

Educating citizens improves not only the individual but also society as a whole in multiple ways. In a report completed by the Education Advisory Board (2008), the advantages resulting from a college-educated person and society include "an increase in tax revenue, individual health and well-being, volunteer work, [and] voting participation" (p. 3) along with "a decrease in poverty levels, unemployment rates, social safety-net programs (e.g., food stamps), narcotics addiction, [and] incarceration rates" (p. 3). Higher education benefits not only the individual, but society as well.

However, access to institutions of higher education is not a guarantee as it is for primary and secondary education in the United States. Higher education is a privilege that one must qualify for. A person must be determined "eligible" to attend through a college admissions process. Traditionally, college and universities have relied heavily on GPA (Grade Point Average) and standardized tests such as the SAT (originally called the Scholastic Aptitude Test or the Scholastic Assessment Test) and the ACT (originally called American College Testing) to assess a prospective students' college preparedness, and ultimately determine admissibility (Hossler \& Anderson, 2005; Studley, 2003; Breland, et al., 2002; Beale, 1970). Yet, research has questioned if standardized tests scores are the most equitable across diverse populations (Walpol, et al., 2005; Noble \& 
Sawyer, 2004) and if GPA is the best predictor of college success Noble \& Sawyer, 2004, Korbin, et al., 2008).

The total college enrollment rate for young adults overall increased from 35 percent in 2000 to 41 percent in 2016, according to the U.S. Department of Education (2019). According to the U.S. Department of Education (2016) since the 1970's, college enrollment for white, non-Hispanic, students has increased, however students from racially diverse backgrounds have not seen a proportionate increase in college enrollment.

As of 2013, in public 4-year institutions, $63 \%$ of students enrolled identify as White, $14 \%$ as Hispanic, $12 \%$ as Black, $7 \%$ as Asian/Pacific Islander and $1 \%$ as Native American (U.S. Department of Education, 2015). The U.S. Department of Education (2019) reports that from 2000 to 2016 , total college enrollment rates increased for White (from 39 to 42 percent), Black (from 31 to 36 percent), and Hispanic young adults (from 22 to 39 percent) but did not show notable increase for any other racial/ethnic groups during this time period.

Enrollment based on gender has been changing for the past 35 years (National Student Clearinghouse, 2018). According to the National Student Clearinghouse, women now account for almost $60 \%$ of college students in the United States and male-identified students account for about 40\%. This gender gap continues to grow. 
It is clear that, by far, the largest enrollment at colleges and universities is by White female-identified students. Increasing access to college education for all citizens is important to meet demands of our changing demographics and extend an educational opportunity to our citizens and advance society.

While some argue that test scores and GPA's measure cognitive abilities of incoming college students, there may be other factors responsible for lower test scores, including family income, poverty level, and education level of parents as well as the fact that schools in lower income neighborhoods tend to have students perform lower on the SAT’s (College Board, 2014; Pew, 2014; Chandler, 2011; Massey, et al., 2003). In addition, research has shown that test scores and GPA alone does not always reflect a student's ability to be successful in college (Noble \& Sawyer, 2004, College Board, 2008). By maintaining the traditional admissions criteria of measuring cognitive variables such as standardized test scores and GPAs to determine admissibility, one can ask if colleges and universities are, in essence, limiting access for diverse student populations.

\section{Significance of a Diverse Student Population}

Admitting a diverse pool of students to college is important as it benefits the individual (Antonio, 2003; Astin, 1993), institutions of higher education (American Council on Education, 2002), and society (Gurin, Dey, Hurtado \& Gurin, 2002). Attending college benefits an individual in multiple ways. According to the Pew Research Center (2014), those who attend college have increased earning potential, lower unemployment rates, and have an overall higher job satisfaction rate than individuals who 
do not attend college. In addition, students and faculty can gain in both experience and knowledge when a campus is intentional in creating a racially diverse environment. In a meta-analysis, Pascarella \& Terenzini (2005) found evidence that an institution with a racially diverse student body, also known as structural diversity, appears to enhance academic and social self-concepts of all students on campus. In the early 2000s higher education research concerning diversity showed "that a diverse student body confers benefits ranging from the development of students' intellectual and social selfconfidence, to exposure to different ideas and viewpoints, to cognitive development and academic achievement” (Antonio, 2003, p. 15). Over 20 years ago, Astin (1993) completed a four-year longitudinal study collecting data on over 24,800 college students. Astin (1993) found that emphasizing diversity, either by institutional structure or through teaching, as well as giving students both curricular and extracurricular experiences dealing with multicultural issues, benefited the cognitive and personal development of all students. Additionally, the American Council on Education (2002), also known as ACE, asserts that a diverse student body is essential to providing a highquality education. ACE states that diversity improves the educational experience, promotes personal growth, and builds stronger communities. In order for students, institutions and society to benefit from diverse enrollment in colleges, students must first be admitted to college. 


\section{Law and Policy}

To increase access to higher education, some schools began utilizing affirmative action in the college admissions process in the 1960's. A part of the civil rights movement, affirmative action policies can be defined as when "... an institution or organization actively engages in efforts to improve opportunities for historically excluded groups in American society" (National Conference of State Legislatures, 2014, para.1). After this was implemented, college enrollment rates for African American and Latino students increased (National Conference of State Legislatures, 2014). Nondiscrimination and affirmative action laws most certainly affect policy regarding student race and admissions within higher education. In fact, over the last 20 years, state and federal courts have issued rulings both for and against affirmative action within undergraduate admissions at selective tier one, public research institutions. For example, in 2003 the Supreme Court made a highly publicized ruling regarding race and admissions at the University of Michigan. In Grutter v. Bollinger (2003) and Gratz v. Bollinger (2003) the Supreme Court noted for state schools that "racial-ethnic origin was a permissible consideration in Admissions provided it was not applied mechanically" (Pascarella \& Terenzini, 2005). Many of the arguments for encouraging diversity within American higher education were used in providing reasoning behind this decision. As recently as 2016, the Supreme Court rejected a challenge to considering race in college Admissions in Fisher v. University of Texas. Ultimately, the court allowed for colleges to continue to consider race, among other factors, in ensuring a diverse student body. 
This ruling noted that race cannot just be assigned a set amount of "points" within the process of admissions. Changes in interpretation are ongoing, however. The Department of Justice and Education, led by the Obama administration, released guidelines allowing for institutions of higher education to use race in the admissions process (Dillon, 2011). The guidelines stated "Post-secondary institutions can voluntarily consider race to further the compelling interest of achieving diversity" (U.S. Department of Justice \& U.S. Department of Education, 2011). This continues to be a significant issue in society as changes in the interpretation of laws surrounding admissions policies occur frequently. Case in point, the Obama administration interpretation and guidelines are in direct opposition to the previous presidential administration's 2008 interpretation of the same Supreme Court ruling. However, as of July 2018, the Trump administration discouraged the use of race in college admissions and revoked the guidance from the Obama administration on affirmative action. Laws and policy regarding college admissions changed over time and new cases continue to be brought to the court system, impacting the history of criteria that universities may consider within their admissions process.

In 2016, the Supreme Court rejected a challenge to considering race in college Admissions in Fisher v. University of Texas. And as recently as 2021, the Supreme Court deferred a case against Harvard on race in college admissions. Ultimately, the court has allowed for colleges to continue to consider race, among other factors, in ensuring a diverse student body. 


\section{Evaluating Student for Admission}

Cognitive variables, or measures of mental perception and intelligence, have been relied on as a predictor of college success. Colleges and universities tend to use GPA and standardized tests such as the SAT and the ACT as a measure of intelligence to determine admissibility to college (Hossler \& Anderson, 2005; Studley, 2003; Breland, et al., 2002; Beale, 1970). There are numerous reasons for this including the perceived ease of a straightforward comparison between numerical results.

Standardized testing. There has been discussion over the past decades on how one measures a student's learning in regards to their preparedness for college. In 1901 the College Entrance Examination Board (now known as the College Board) administered its first assessment (Sedlacek W. E., 2004). In 1926 the first Scholastic Aptitude Test (SAT) was offered, was mainly multiple-choice, and $60 \%$ of those taking the test were males (Public Broadcasting System, 2015). Due to a global pandemic, 2020 was the first year since the 1900's when the SAT was not offered to college bound students.

Institutions of higher education are still utilizing basically the same measure of what is perceived to be college readiness, which includes perceived level of college-level intelligence. While our measurements of college preparedness haven't changed very much, our students, our institutions, and our world have changed over the past 120 years.

Research on college entrance exams has exposed many kinds of bias (Walpole, et al., 2005). In a side-by-side comparison of the 2010 SAT scores of college bound seniors (Fair Test, n.d.) major discrepancies in SAT scores based on gender, ethnicity and income were identified. In the study, males scored higher than females, Asian American 
and White students scored higher than other ethnic groups, and students who reported a higher family income scored higher on the test. ACT test scores have similar reports in 2010 with men scoring higher than women and Asian American and White students scoring higher than other ethnic groups (Fair Test, n.d.). According to The College Board in 2018, SAT combined scores for both White and Asian students had an average of over 1100. All other racial demographics averaged below 1000.

In regards to gender, in 2019 (The College Board) males outscored women in the SAT math test. This is a similar trend to previous years. SAT total scores were also higher for males than females. In 2019 (The College Board) males scored an average of 1066 total on the SAT while females scored an average of 1053.

Research has been conducted to try and determine what may be behind these differences in standardized test scores. According to a report by Education Partnerships, Inc. (2010) most researchers explore differences in test scores based on four things: student characteristics (GPA, attendance patterns, motivations, perception of self, extracurricular activities, etc.), family characteristics (family structure, parents level of education, etc.), school-based characteristics (class size, curriculum, etc.), and sociocultural factors (racism, cultural attitudes). Of these four options, student characteristics tend to have the most impact on standardized test scores while family characteristics have the second most impact (Anderson, 2010). In particular, first generation college students, or students whose parents had not attended college, tend to score lower on college entrance exams (Crosnoe \& Muller, 2013; Pascarella et al 2004). The highest rate of first- 
generation college students is underrepresented minority groups (U.S. Department of Education, 2012).

Grade point average and beyond. High school GPA has been recognized as a predictor of college readiness and academic success (Astin, 1993; Schwartz \& Washington, 2002; Ting, 1998). However, there are some concerns around using GPA as a stand-alone measure of college readiness due to the potential of grade inflation.

According to the National Assessment of Educational Progress (NAEP) High School Transcript Study (HSTS), the mean GPA for high school graduates has increased from a 2.86 in 1990 to a 2.94 in 2000 (2009). The same study shows the mean GPA for women is higher than that for men and that students on the West coast consistently have higher GPAs than those in the Northeast and Midwest. Asian-American students had the highest overall mean GPA of 3.2, followed by White students with a 3.1 overall mean GPA, while Hispanic students earned a 2.8 overall mean GPA and Black students earned a 2.63 mean GPA. (NAEP, 2010). In the year 2000, private school students earned a higher GPA than their counterparts at public high schools (NAEP, 2010). The National Center for Educational Statistics (2010) explains that multiple factors may have contributed to the discrepancies in GPA's over the years such as "... changes in teachers standards for grading, changes in material taught for courses, or other factors that cannot be measured by the [High School Transcript Study]" (p. 3-14).

Nontraditional admissions criteria. Researchers have investigated other factors that might influence college readiness, including nonacademic personality traits. Tross, Harper, Osher and Kneidinger (2000) found that conscientiousness, defined by being 
thorough and self-disciplined, was a better predictor of first to second year retention of college students versus high school GPA. Study motivation can also play a role in student success in college (Melancon, 2002). A meta-analysis by Crede \& Kuncel in 2008 found factors such as study habits, study skills, motivation to study, and attitude around studying rivaled high school GPA as a predictor of college success.

All of the above-mentioned traits are non-cognitive. Sedlacek (1996) defines noncognitive variables as "motivation, experiences, and background variables that educators might agree are important, but that may not be measured in a systematic way by a standardized test or by previous grades" (Sedlacek W. E., 1996, p. 79). Given that we know that students from diverse backgrounds do not perform as well on cognitive measures such as standardized testing (Waldpole, et al, 2005) and GPA (Noble \& Sawyer, 2004) as their dominant counterparts, it may be useful to consider non-cognitive measures as a potentially better predictor of college success for diverse students.

Looking beyond the cognitive variables of test scores and GPA could expose new dimensions of college preparedness. Considering non-cognitive variables as a part of the Admissions process is a potential solution in increasing enrollment in college. A student's motivation, past experiences, and personality traits may, in fact, aid in selecting a diverse group of prepared students for college admissions. Some colleges and universities have started to consider non-cognitive variables within their selection process, but more research about the impact this has on college admissions and student retention, once admitted, is necessary to understand implications of using non-cognitive variables in the admissions process. 


\section{Proposed Study}

This proposed study seeks to explore the impact of using non-cognitive factors on college admission and retention of students who are admitted to college while academically atrisk. Academically at-risk means they are entering this university with a GPA below 3.0, low test scores, or without fulfilling all preparatory course requirements. In order to explore this, the researcher will consider data from a 4-year research institution located in the Pacific Northwest. At this university, students are typically admitted if they have a high school GPA of 3.0, take either the SAT or ACT, and have completed preparatory courses in English, Math, Social Studies, Science and Foreign Language, and complete admissions essays. Applicants are asked to complete essays as a measure of noncognitive assessment. These short essays, referred to as an Insight Resume, are based on eight non-cognitive variables that consider the following traits: "positive self-concept or confidence; realistic self-appraisal, especially academic; understands and deals with racism; prefers long-range goals to short-term or immediate needs; availability of a strong support person; demonstrated community service; and knowledge acquired in a field." At this institution, students who do not meet basic admissions requirements, and are therefore not admitted, may challenge an admissions denial by filing an appeal. This process is known as "extended admissions." Often, those appealing admissions decisions are doing so because they do not meet the minimum GPA requirement, have not submitted test scores, or do not meet preparatory course requirements.

Some universities have a process to admit academically at-risk students who do not meet either test score or GPA minimums. These students, who do not meet minimum 
admissions requirements, are often referred to as "academically at-risk." Research of academically at-risk students admitted to universities show predictors of their success go beyond SAT scores and high school GPA to include such factors as previous leadership experience (Mattson, 2007), a strong sense of self (Pizzolato, 2003), realistic selfappraisal and understanding and coping with racism (Adebayo, 2008). The predictors mentioned here could be considered These non-cognitive, or nonacademic, variables will be discussed at length later in this research.

This study will consider students admitted to the university through the extended admissions process. These students would be seen as "academically at-risk" due to their lower high school GPA, lower test scores, and/or missing preparatory requirements. The researcher will also consider demographic characteristics (race, gender, residency status and legacy) to consider correlations between characteristics and admission and retention. This study seeks to explore the predictive ability of non-cognitive factors in admission and first-to-second year retention of academically at-risk students.

Chapter two will include a detailed review of demographics at institutions of higher education, as well as an expanded discussion of the importance of diversity on college campuses relating to changing demographics. Related learning theory will be explored, as will current law and policy practices surrounding college admissions. Finally, chapter two will address the history of college admissions and the recent infusion on non-traditional admissions criteria. 


\section{Chapter Two: Literature Review}

A review of literature will explore current concerns regarding access to higher education for academically at-risk students in the current standard college admissions process. Issues considered are the current state of enrollment in the United States and American institutions of higher education; related learning theory; law, legislation and policy; history of admissions criteria and the discussion around equity within the process; and finally, the development of nontraditional admissions criteria.

\section{Demographic Shifts}

According to the 2020 U.S. Census, the United States has seen a population increase of 10.1 percent between 2010 and 2020. The largest percentage of growth came from those who reported their race(s) as something other than White alone and those who reported their ethnicity as Hispanic or Latino (U.S. Census Bureau, 2020). Between 1994 (the first year for which high school graduate data were available for all regions) and 2005 (the last year for which the actual numbers of graduates were available) all regions of the United States experienced increases in the number of students graduating from a public high school (College Board, n.d.). Despite lower high school graduation rates and lower college-going rates than Whites, the actual numbers of minorities enrolled in college have increased because of growth in the size of the minority populations, yet not nearly as proportionally as their white counterparts. In fact, the U.S. Department of Education (2013) reported that in public 4-year institutions, 63\% of students enrolled 
identify as White, $14 \%$ as Hispanic, $12 \%$ as Black, $7 \%$ as Asian/Pacific Islander and 1\% as Native American.

Current admissions practice in the United States tends to have a heavy focus on using cognitive variables such as standardized tests and GPA to determine college preparedness, however research shows this may not be the most equitable measure of college readiness (Walpole, et al., 2005: Noble \& Sawyer; 2004, Sedlack, 2006). Creating a climate where admissions policies and practices acknowledge and provide ways to minimize the bias inherent in standardized tests and GPA requires vigilance and institutional resolution. Admitting a diverse pool of students to college is beneficial to individuals (Antonio, 2003; Astin, 1993), institutions of higher education American Council on Education, 2002; Pascarella \& Terenzini, 2005), and society as a whole (Gurin, Dey, Hurtado \& Gurin, 2002,).

Increasing access to higher education benefits individuals, college campuses, and society. Individuals who obtain a college degree have lower unemployment rates, higher salaries earnings, feel they are more prepared to be successful in their job, and have higher job satisfaction rates (Pew, 2014). College campuses benefit from a diverse student body in multiple ways. Pascarella \& Terenzini (2005) conducted a meta-analysis and found institutions with structural diversity have a positive effect on student's selfconcept, academically and socially. Additionally, Chang (1996) discovered that a diverse student body on college campuses contributes to an institutional climate that exhibits a stronger focus on multiculturalism, a larger faculty emphasis on racial and gender issues in both research and in the classroom, and increased student participation in cultural 
awareness workshops and ethnic studies courses. Other research has shown social interaction across racial lines and involvement in dialogue about racial issues have indicated positive beneficial effects on a student's educational and personal development, regardless of race (Astin 1993; Villalpando 1994).

\section{Related Learning Theory}

Understanding how one might find the variance that students' GPAs and test scores present is important in determining the impact on admissions to higher education. A discussion of learning theory follows. Constructivism is a learning theory that strives to explain how people make sense of their experiences ("Constructionism (learning theory)", n.d.). This involves a combination of a learner's cognitive skills with the learner's environmental interactions. Using a constructivist lens to consider a student's learning allows one to consider issues that could negatively impact a student's standardized test score or GPA, beyond rote knowledge. In order to better understand constructivism, it is important to describe the work of four people who provided the developmental theories responsible for the base on the concept of constructivism.

John Dewey was a founding father of constructivist theory. His original work in 1940 promoted the importance of personal experience in learning (Lutz \& Huitt, 2004). He theorized that learners make meaning of the world due to experiences with their environment. His work set a base for further research, like that of Jean Piaget in the 1950's. Piaget believed that "cognition is grounded in the interface between mind and environment" (Lutz \& Huitt, 2004, p. 7), and that individuals progressed through 
schemata, or stages, which become more complex as an individual develops intellectually. Piaget's work focused on children and the cognitive maturation process, as well as the role the environment played in that development. Piaget believed that cognitive development was a mixture of an individual's mind and environment (Lutz \& Huitt, 2004). Then, in the 1970's, Lev Vygotsky took the constructivist concept one-step further by exploring how society and culture impact cognitive development. Vygotsky believed social interaction was the heaviest influence on learning and development, in that "human beings create cultures through the use of cultural tools. Culture (and in turn society) then dictates what is valuable to learn and how it is learned" (Lutz \& Huit, 2004, p. 6). Vgotsky believed society was the motivating force behind cognitive development. Finally, in the late 1980's Jerome Bruner included many of the concepts from previous theories in his work, yet he did not focus on putting cognitive development in to stages that were age-related. Bruner found culture to be a critical aspect of learning and believed stages should not be expected to be present across cultures (Lutz \& Huit, 2004). This brings up an interesting contradiction between the basis for constructivism and current college admissions practices. As previously discussed, standardized test scores are thought to measure cognitive competence for college, yet they have shown to be culturally biased, however constructivist theory says that the impact of culture and society on cognitive development cannot be ignored. This calls in to question the disparity in the current process of college admissions. Currently test scores and GPA are thought to measure college preparedness on an intellectual level, but, using the lens of 
constructivism, one can see that this analysis does not take in to account diverse experiences and the impact of environment on college applicants.

To illustrate, consider Sternberg’s $(1985,1986)$ Triarchic Theory of Intelligence in looking at intelligence tests within the college admissions process. He explained a connection might exist between traditional cognitive experiences and the non-cognitive. He suggested that there are three ways a person shows ability...through metacomponents, performance components, and knowledge-acquisition components. According to Sternberg $(1985,1986)$ this componential intelligence is essentially the ability to understand material hierarchically and taxonomically in a static context. This is a skill associated with a conventional experience in our society. If a person's experience was not fairly stable, or if their context was other than traditional, they may be more likely to struggle showing ability in this way. Traditional college admission measures (standardized tests and prior GPA) rely greatly on this type of intelligence.

In his more recent work, Successful Intelligence, Sternberg (1999) argues that intelligence is "the ability to achieve success in life, given one's personal standards, within one's sociocultural context" (p. 293). Sternberg (1999) contends that in order to achieve success a person must utilize their strengths, be aware of and compensate for their weaknesses, and have the capacity to adapt to and shape their environment. In his writing on Successful Intelligence, Sternberg (1999) argues that the conventional ways we measure "intelligence" do not take in to account the broader sense of what intelligence may mean...that while tests of intelligence may measure analytic or academic understanding, they do not take in to account practical intelligence, creative 
intelligence, or cultural components of one's whole self. This relates to the use of noncognitive variables in the college admissions process. While traditionally tests and GPA have been thought to be ways of measuring intelligence, Sternberg argues we must look beyond those to understand a more holistic view of intelligence. This is the exact purpose behind using non-cognitive variables in the college admissions process.

Claude M. Steel (1997) developed a theory that speaks to the impact of environment and culture on learning. His theory of Stereotype Threat considers achievement barriers for students of color and women based on their identities, the societal pressures prescribed to those identities, and internalized judgments and pressures put on oneself due to those identities. Research indicates, “...this threat dramatically depresses the standardized test performance of women and African Americans who are in the academic vanguard of their groups (offering a new interpretation of group differences in standardized test performance)" (Steel, 1997, p. 163). Steel conducted research by measuring outcomes of both women and minority students on various tests. When told the tests measure intelligence, women and minority students would perform poorly. When told the test did not measure intelligence (therefore removing internalized societal and socialized barriers), women and minority students performed just as well as, if not better than their white male counterparts. This theory may go to support that poor test performance may not just be due to intelligence levels alone.

In the United States, our current practice in college admissions focuses on what are considered measurable variables of student success...test scores and previous grades (Hossler, 2005). Traditionally, within the admissions process colleges and universities 
have rewarded students based on cognitive success, but have not tended to honor their achievements of developmental competencies. In remembering "theory is a starting point, not an end point" (C. Reynolds, personnel communication, 2010), we can use the knowledge base which understanding learning theories gives us in order to utilize theories to start to shape more inclusive college admissions processes.

\section{The College Admissions Process}

The number of students attending college in the United States has grown dramatically over the past fifty years. Prior to the 1950's, less than two of every 10 students graduating from high school attended college (Palmer, et al., 2004). According to Palmer et al (2004), in the 1940's and 50's college selection was straightforward as incoming students chose from a limited and defined set of institutions. However, as the G.I. Bill came into play and more students began to apply to colleges " ...the increase in the college-going population forced colleges and universities to become more sophisticated and streamline their admissions and administrative practices" (Palmer, et al., 2004, p.2). It was at this time member institutions of the College Board chose a common application date, which began to standardize process across institutions (Palmer, et al., 2004).

In the mid-19 $9^{\text {th }}$ century, college admissions were based on if a student was in good standing at their high school because so few could afford to attend (Ryan, 2013). Tufts University historical admissions documents states "Applicants for admission must produce certificates of their good moral character" and pass an exam in Latin, Greek, 
math and history. If a student passed tests they were to pay $\$ 200$ (approximately $\$ 5,000$ in 2013 dollars) in order to officially be admitted (Ryan, 2013). It wasn't just Tufts during the seventeenth and eighteenth centuries prospective college students were assessed on their character, background, and proficiency in Latin and Greek (Beale, 1970). As time progressed, the college admissions process still relied on standardized tests, but each institution administered their own tests. By the mid-nineteenth century, there were still no significant agreements between colleges as to what admissions requirements should be. In 1900, a committee was formed by the National Education Association to consider college entrance requirements and accrediting agencies were instituted in an attempt to make college entrance requirements more uniform across the country (Beale, 1970). In 1926, the Scholastic Aptitude Test (SAT) was given to high school students for the first time (Oregon Public Broadcasting, 2014). According to Beale (1970), by the mid-1900's, most colleges and universities requirements were fairly standard across institutions and constituted of:

- High School diploma,

- A certain number of required basic curriculum classes,

- Class rank,

- Recommendation from teacher,

- Personal interview,

- Standardized test scores. 
Since the mid-1900's, requirements for college admissions have not changed much from that. Some argue standardizing admissions requirements makes it easier on the institution to make selections due to the large number of applicants.

In the book Images of Organization by Gareth Morgan (2006), the use of metaphor is utilized to describe "a way of thinking and a way of seeing" (p.4) organizations from various theoretical lenses. Morgan (2006) describes the metaphor of organization as machine as "bureaucracies [that]...operate as if they were machines: in a routinized, efficient, reliable, and predictable way" (p. 13). Organizations as machines are hierarchical with in depth rules and regulations (Morgan, 2006). This metaphor brings to mind of employees acting as a machine would by following rules, policies, and regulation in a mindless manner. Parallels from this metaphor may be made to offices of admissions at institutions of higher education. Usually, every student application is put through the same process, measured by set standards, and there is not room for flexibility because rules and policies are strictly followed and enforced. This may seem, then, the most practical way for institutions to process a large number of college applications in an efficient and seemingly equitable manner. If a student scores $\mathrm{X}$ and has a high school GPA of Y, they are admitted. Similarly, administration of standardized tests could be seen as a machine as well. The SAT/ACT can be administered to a sizable amount of students concurrently and are proficiently and impartially scored. However, as previously discussed, we know that racially diverse students are usually at a disadvantage when it comes to simply using test scores for college admissions (Sackett, Schmitt, Ellingson, \& Kabin, 2001). 
The college admissions process is set by each individual institution, and varies based on institutional type (Lucido, 2015). For instance - public institutions will have different practices than private institutions. Land Grant universities will have a different practice than small liberal arts institutions. This is because the institution must consider their mission when they deliberate what students to admit (Lucido, 2015). While there are some variances in the admissions process based on institution, all institutions must be aware of laws and policies that impact the admissions process.

\section{Law, legislation, policy, and issues of relevance}

There are laws and policies in place currently that impact an institution's admissions practice. This is both on a federal level and a state level. Public institutions, like TTSU, must follow both federal and state laws and policies.

\section{Policy framework.}

Before discussing specific policies and laws related to college admissions, it is important to first explore what is policy, what influences policy, and how do policies relate to laws? Fowler (2004) argues that the major values in the United States that influence policy are self-interest values, general social values, democratic values, and economic values. An example of this relating to college admissions is the way in which current economic issues can influence admissions policies. Steven Brink of the Washington Post (2010) noted that some institutions are increasing out-of-state student admits to their universities in order to increase revenue. Additionally, some schools are inching away from using a need-blind approach during the admissions process and 
instead considering a student's ability to pay full tuition within the process (Brink, 2010). While utilizing a need-blind approach is an institutional policy decision, it is easy to see how current values such as an institution's economic issues can affect institutional admissions policy.

Policies can vary from one institution of higher education to another, depending on institutional size, scope, university leadership and mission. However, there are some broader policies that affect institutions of higher education across the board. The American Association of State Colleges and Universities annually publishes a report titled "Top 10 Higher Education State Policy Issues" that outlines current public higher education policy. In 2020, two of the ten policy issues in the aforementioned report have implications for college admissions.

First, states' fiscal crises which means less money is coming from the state to the public colleges and universities, therefore raising tuition for students and decreasing accessibility. This is not a new concern - in fact, in the United States in 2010, 36\% of funding for higher education was public while $48 \%$ came from households (tuition) and $16 \%$ was from other private sources (College Board, 2013). Attending college is expensive and the bulk of the burden falls on the individual.

The second implication in the report is related to demographics. Demographic changes, particularly a recent decline in college enrollment, are of large concern for both higher education administrators and state policymakers. The high school aged population is declining across the country. This could lead to a more competitive admission process 
between institutions, and should increase focus of institutions on retention of their enrolled students.

There are also professional policies that guide the work of those in the college admissions. The American Association of Collegiate Registrars and Admissions Officers (AACRO) is a non-profit organization with a mission to "... serve and advance higher education by providing leadership in academic and enrollment services" (2010, para. 1). Professionals who work in college admissions offices may choose to become a member of this organization and as such are expected to follow AACRO's Statement of Professional Ethics and Practice. Part of this statement insists admissions professionals "Promote broad and equal access to higher education for qualified students" (2010, para. 3) and to "Adhere to principles of nondiscrimination and equality within the framework of institutional mission and prevailing law" (2010, para. 3). Therefore, policies of professional organizations support access to higher education for diverse student populations. No matter what policy is in place, however, one must consider how policies are held and created in relation to the laws.

Legal implications. In addition to ideologies and values, policy also ties in with law. Policy is related to law, but they are not one in the same. A law is actually a statute passed by either the state or federal government (Kaplin \& Lee, 2009). Laws include specific legislation.

Over the years, there have been multiple Supreme Court decisions in regards to using race within the Admissions process. Historically, nondiscrimination and affirmative 
action laws most certainly affect policy regarding student race and admissions within higher education.

The most relevant and earliest case dates back to1896 when the Plessy $v$. Ferguson case upheld racial segregation and lead to the "separate but equal" doctrine that carried over in to public schools (Moreno, 2003). Almost fifty years later Brown v. Board of Education (1954) put a legal end to racial segregation in public schools, which, although was technically concerning elementary and high school had a consequence for colleges and universities as it set the stage for the Civil Rights Act of 1964 (Kaplin \& Lee, 2009). Title VI of the Civil Rights Act ordered desegregation of all public schools, including institutions of higher education by declaring that no institution of higher education (public or private) could discriminate within admissions policy based on race (Kaplin \& Lee, 2009). College admissions policies had to be established (or perhaps unestablished) in order to support this ruling.

In 1978 litigation in Regents of the University of California v. Bakke established that race could actually be used as a factor in college admissions (Kaplin \& Lee, 2009). In his opinion, Justice Harry Blackmun eloquently made an argument for the support of considering race in college admissions process:

I suspect that it would be impossible to arrange an affirmative action program in a racially neutral way and have it successful. To ask that this be so is to demand the impossible. In order to get beyond racism, we must first take account of race. There is no other way. And in order to treat some persons equally, we must treat 
them differently. We cannot - dare not-let the Equal Protection Clause perpetuate racial supremacy (U.S. Supreme Court, 1978).

In Grutter v. Bollinger (2003) and Gratz v. Bollinger (2003) the Supreme Court upheld the Bakke decision, noting for state schools "racial-ethnic origin was a permissible consideration in Admissions provided it was not applied mechanically" (Pascarella \& Terenzini, 2005). The benefits that may be achieved by having a diverse study body provided the reasoning behind this decision. The Supreme Court was once again asked to rule on race in the college Admissions process in the Spring of 2013 for Fisher $v$. University of Texas. While the Supreme Court's opinion validated the benefits of diversity in a college setting, the case was remanded back to the lower court for further proceedings.

Legislation: affirmative action. Affirmative action is defined by Merriam-Webster as "the practice of improving the educational and job opportunities of members of groups that have not been treated fairly in the past because of their race, sex, etc." ("Affirmative Action," n.d.). Legislation in the United States to implement affirmative action began during the Kennedy Administration when President Kennedy issued Executive Order 10925 (Brunner \& Rowen, 2007). This executive order applied to employment pushing for hiring practices to be free of racial bias. Affirmative action progressed when President Johnson signed the Civil Rights Act in 1964, prohibiting discrimination based on based on race, color, religion, or national origin (Brunner \& Rowen, 2007). Affirmative action within higher education was first brought to the spotlight in the aforementioned 
University of California v. Bakke case. Currently, affirmative action legislation still stands within higher education, although specific laws vary from state to state.

Each state government operates differently in establishing admissions policy for postsecondary institutions. For example, in the state of Oregon the state legislature authorizes public institutions to adopt administrative rules. These rules include "directives, standards, regulations or statements of general applicability that implement, interpret or prescribe law or policy or describe the agency's procedure or practice requirements" (Oregon University System, 2010). Admissions policy for public institutions of higher education would be included in this definition of state rules. While public institutions may set admissions policies, public policy and legislation still plays an influential role. Policies and laws impact the college admissions process on both a federal and a state level. When policies and laws change the college admissions process may be impacted.

As Peter Lake (2011) states in Foundations of Higher Education Law \& Policy "Creating and maintaining a diverse, vibrant, and inclusive student population turns on highly individualized assessment. Students are not categories or boxes they check; categorical information might help, but inclusion and diversity require the use of judgment and individualized assessment" (p. 237). The common Admissions practice of using the same numerical measure of test score and/or GPA, without considering individual differences and backgrounds, is an example of an organization acting as machine as historically, individualized assessment has not been used as Admissions criteria. 


\section{Admissions Criteria}

In the United States, the current practice in college admissions focuses on what are considered empirically measurable variables of student success...test scores and previous grades. In the national survey of undergraduate admission policies, practices, and procedures it was reported that four-year institutions use high-school GPA (as well as strength of curriculum/grades in college preparatory course) and admission test scores as the most important factor in college admissions (Breland, Maxey, Gernand, Cumming, \& Trapani, 2002). However, one might consider “...if different groups have different experiences and different ways of presenting their capabilities, it is unlikely that a single measure, test item, and so forth could be developed that would result in equally fair outcomes for all” (Sedlacek W. E., 2003, p. 264).

According to AACRAO (2015), colleges and universities that utilize noncognitive measures in their admissions process show a connection to student retention and graduation. The National Center for Educational Statistics (NCES, 2011) defined retention rate as the percentage of first-time, degree-seeking students who returned to college the fall term after their first year. For the purposes of this study, student retention will be defined in this way. There have been multiple studies on non-cognitive factors as they relate to student retention such as student's involvement with faculty, peers, and perceived institutional support (Berger \& Milem, 1999), participation in an institutional first-year program (Jamelske, 2009), and use of school resources and risk taking (Robbins et al., 2009). Also, research indicates personal goals and commitments (Pascarella \& 
Terenzini, 1980) and institutional allegiance (Bean, 1980; Pascarella \& Terenzini, 1980) also play a role in student retention.

Studies have also looked at specific student populations and the impact of noncognitive variables on their retention. Sedlack (1992) found non-cognitive variables were more reliable in predicting retention over SAT scores for student athletes. Tracey \& Sedlack (1987) found non-cognitive variables were a better predictor for AfricanAmerican student retention than for their White peers. Ting (2000) found realistic selfappraisal to have a positive predictive effect on Asian-American students. Additionally, White and Sedlack (1986) found successful leadership experiences and positive selfconcept had a positive correlation in predicting student retention of specially admitted students. Measuring non-cognitive variables for admittance into institutions of higher education is not a new concept.

In 2002 McMaster University, a medical school, instituted Multiple Mini Interviews (MMI's) to assess communication skills that are not easily measured by test scores or previous academic performance (McMaster University, 2021) MMI's are meant to assess competencies needed by aspiring doctors such as teamwork, verbal communication, and both non-verbal and social skills. This measure of non-cognitive variables is now utilized in multiple medical school admissions process across the United States and Canada (AAMC, 2021)

Current practice in the college admissions process. Traditionally, college and universities have relied heavily on measuring cognitive aspects of a potential student through GPA (Grade Point Average) and standardized tests such as the SAT (formally 
called the Scholastic Aptitude Test or the Scholastic Assessment Test) and the ACT (originally called American College Testing) to determine admissibility (Hossler \& Anderson, 2005; Breland, et al., 2002; Beale, 1970). However, over 815 four-year colleges and universities across the U.S., acting on the belief that 'test scores do not equal merit,' do not use the SAT or ACT to make admissions decisions about a substantial number of their incoming freshmen classes (National Center Fair \& Opening Testing, n.d.). Some institutions also consider written essays, interviews, teacher recommendations and strength of prior curriculum within their process (M. Sandlin, personal communication). In an effort to consider diversity within the college admissions process while complying with laws and policies, some colleges have leaned away from common and historical practice.

California, Florida and Texas in an effort to forgo race-based admissions, have instituted a percentage plan for their in-state students. Admissions to in-state colleges are offered to a top percentage of graduating seniors based on GPA, and therefore class standing, alone (Casement, 2001). The hope is the percentage plan would create an equitable racial composition on campus that mimics the racial make-up of the state (Long, 2004). Even though the percentage plan was put forward as a new solution to affirmative action, there is still a lack of consideration for individual variables. High school GPA is the only factor that is taken in to account in the percentage-plan system. Some colleges and universities have begun to use non-cognitive variables within their admissions process. 
What are non-cognitive measures? Defining the term non-cognitive can be challenging, as there are multiple aspects to what one can measure to determine non-cognitive skills. However, most research refers to traits and skills one may possess such as critical thinking skills, problem solving skills, social skills, persistence, creativity, and selfcontrol. A non-cognitive variable can be defined as a trait not directly related to cognition (i.e. knowing and/or remembering). Measuring these traits can be done in multiple ways and, in fact, it is recommended that multiple methods be used to measure non-cognitive variables within the college admissions process (Sedlacek W. E., 2003). Some methods of measuring non-cognitive traits include questionnaires, portfolios, essays, and interviews.

A review of current literature demonstrates there are many examples of institutions and programs that use non-cognitive assessment in the student selection process. For example, the Gates Millennium Scholars program weighs $80 \%$ of its application on the scoring of non-cognitive variables (Sedlacek W., in press). Oregon State University (OSU) employs the use of non-cognitive variables in the admissions process through an "Insight Resume." The OSU Admissions application has a shortanswer essay section that asks students to complete 6 short-answer essays based on the eight non-cognitive variables in the NCQ (Sedlacek, W., in press). Northeastern University in Boston utilizes non-cognitive assessment in selection for their Torch Scholars Program to select students who most likely would not qualify for admissions with GPA or test scores but have overcome adversity (Tomsho, 2009). 90\% of these students are retained from freshman to sophomore year though their SAT scores are 
typically 200 points below their fellow Northeastern students (Tomsho, 2009). Also, recently the College Board (which administers the SAT) has announced a new system "designed to focus letters of recommendation on non-cognitive qualities that may not be sufficiently recognized in other admissions criteria" (Jaschik, 2010). Those writing letters of recommendation will be guided by a series of prompts focused on non-cognitive variables to address student achievements that may not necessarily show up in grades or test scores. This is currently in place for some professional schools but will be rolled out for more schools in the future (Jaschik, 2010).

A specific example of a way in which non-cognitive variables have been assessed is the non-cognitive questionnaire (NCQ). The NCQ is based on eight non-cognitive variables that consider the following traits:

- Positive self-concept or confidence

- Realistic self-appraisal, especially academic

- Understands and deals with racism

- Prefers long-range goals to short-term or immediate needs

- Availability of a strong support person

- Demonstrated community service

- Knowledge acquired in a field (Sedlacek W. E., Beyond the Big Test, 2004).

The NCQ has been recognized to have validity in evaluating the dimensions of eight noncognitive variables, and in predicting the retention of nontraditional students (Sedlacek W. E., 2004; Ting \& Robinson, 1998; Ting, 1997). In a study of the NCQ published by Siu-Man Raymond Ting in 1997, specially admitted students were assessed for academic 
success after their admissions based on non-cognitive variables. The students studied were "special admits" because they were conditionally admitted to the university based on their low ACT composite scores and a ranking in the lower $40 \%$ of their high school classes. Implications of this study found that standardized test scores alone were inadequate predictors for first year academic achievement of the students in the study and that using a combination of cognitive and non-cognitive variables could better predict student success and retention (Ting, 1997, p. 408). Further research by Ting and Robinson (1998) shows variance between gender and racial groups in the use of noncognitive variables for college admissions. Both studies recommend a combination of cognitive and non-cognitive measures in the admissions process of colleges and universities.

\section{First to second year retention}

Because this research is focusing on not just admission to college, but first to second year retention, it is important to note that some demographic characteristics are shown to have an impact on college student retention. For the purposes of this research first to second year retention is defined as a first-time, first-year undergraduate student who continues to enroll at the institution from fall of their first term through fall of their second term.

From research, we know that out-of-state students are harder to retain than instate students (Murtaugh, et al., 1999; Yu, 2007). Additionally, BIPOC students have traditionally had lower retention rates then white students (Baker \& Robnett, 2012; 
Reason, 2003) and first-generation students are also known to have a lower retention rate (Ishitani, 2003).

\section{Summary}

This chapter included a review of literature to access to higher education for academically at-risk students given the current standard college admissions process. Issues discussed in this chapter included current demographic shifts in the United State and American institutions of higher education. The current college admissions practice was reviewed, as well as law, legislation and policies surrounding college admissions. A history of admissions criteria and the discussion around equality within that process were identified, as well as related learning theory. This chapter also addressed admission and retention issues related to demographics such as race, gender, residency status and legacy. Finally, this chapter discussed the more recent development of nontraditional admissions criteria.

The review of literature will help the researcher explore if a relationship exists between or among measures of non-cognitive traits for academically at-risk students and first-to-second year retention, or re-enrollment. The following chapter will discuss research methodologies and strategies that will be used to explore these questions. 


\section{Chapter Three: Methodology}

The purpose of the study is to explore the impact of admissions practices on firstto-second year retention of academically at-risk students. The review of literature in Chapter 2 discussed problems in practice within the college admissions process that ensure access to higher education for a wide variety of students and explored why using non-cognitive variables in the college admissions process may assist in measuring traits that could lead to retention for students. This chapter will present research questions and describe the research philosophy and procedures to explore the impact of an alternative to the traditional college admissions process. This chapter also shares information about participants. Main components of the research will be addressed, research strategy used to collect and analyze data. Strengths and weaknesses of research methods as well as research limitations will be discussed.

\section{Research Questions}

In this study, the researcher will seek to answer the following questions:

1. What underlying demographic variables of admitted students reliably predict admission type?

2. What college admission test scores, high school GPA, and IR test scores of admitted students reliably predict admission type?

3. What underlying combination of college admission test scores, demographic characteristics, high school GPA, and IR scores of admitted students, reliably predict placement admission type? 
4. What underlying demographic variables of admitted students and admissions type reliably predict first-to-second year retention of freshman students

5. What college admission test scores, high school GPA, and IR test scores of admitted students predict first-to-second year retention of freshman students?

6. What underlying combination of demographic variables, admission type, high school GPA, and IR scores reliably predict first-to-second year retention of freshman students?

7. To what extent do the underlying combination of college admission test scores, admission type, demographic characteristics, high school GPA, and Insight Resume scores reliably predict first-to-second year retention of freshman students?

\section{Research Philosophy and Approach}

The process of conducting research to interpret outcomes can be explained as a research paradigm (Henning et al, 2004). Simply stated, it is a tactic to consider and direct research. This study utilizes a quantitative research method. The main aspect of quantitative research methods is the data are in numeric terms and outcomes are a result of the analysis of those numbers. The quantitative approach is not only useful, but some consider it to be indispensable in most types of research as it has a strong historical base in "modern empirical, verifiable observation" (Best and Kahn, 2003, p. 278). Descriptive statistical procedures will be used to analyze measures of center, spread, and shape of the entire population and underlying demographic groups. Inferential statistical procedures 
based on sampling distributions will be used to test research questions (Salkind and Frey, 2020).

This is an exploratory study to examine if the use of non-traditional admissions procedures like the Insight Resume has an impact on admission to college and first-tosecond year retention of freshman students.

\section{Data Collection}

This research focuses on the impact of non-cognitive variables on the college admission process. For this study, the Insight Resume is the measurement of noncognitive variables. The Insight Resume are short essays questions that students applying for admission complete. It seeks to measure eight non-cognitive variables: positive selfconcept or confidence; realistic self-appraisal, especially academic; understands and deals with racism; prefers long-range goals to short-term or immediate needs; availability of a strong support person; demonstrated community service; and knowledge acquired in a field. These variables are believed to be a way one can look beyond test scores and GPA in admissions, as well as traits that assist a student in being more prepared for, and therefore retained, at college.

The Insight Resume is a non-cognitive assessment based on the principles of noncognitive Questionnaire (NCQ), developed by William Sedlacek. The NCQ is based on eight non-cognitive variables that consider the following traits: Positive self-concept or confidence; Realistic self-appraisal, especially academic; Understands and deals with 
racism; Prefers long-range goals to short-term or immediate needs; Availability of a strong support person; Demonstrated community service; Knowledge acquired in a field. (Sedlacek, 2004). The Insight Resume used at TTSU asks incoming students to complete 6 short answer essay questions, keeping their answers to 100 words or less. Students are asked to write on their past leadership involvement, knowledge in a field/creativity, experience dealing with adversity, community service, handling systemic changes, and goals/task commitment. Trained readers score these short essays on a scale of 0-3 and this Insight Resume score is entered as a part of the applicant's admissions record. A score is recorded for both the individual essays, as well as an overall Insight Resume score for a combined total of all 6 essays. For this study, the combined score was included in the data set.

TTSU has modified how they utilize Insight Resume scores in the Admissions process since they first included it in their Admissions process. Currently, while all students must complete the Insight Resume as part of the process, the scores are more heavily considered for students going through an extended Admissions process, or admission by committee. Students who do not meet general admissions criteria of GPA or test scores go through this committee process.

\section{Participants}

The participants of the study were the entering first-time freshman classes of a large research intensive (Carnegie R1) public land-grant institution located in the Pacific northwest region of the United States. The researcher developed a fictitious name of Tall 
Tree State University (TTSU) for the university to protect the identity of the college from which the data was gathered. Total full-time enrollment of undergraduate and graduate students is about 23,000. Part-time enrollment is approximately 9,000 students. Enrollment spans across two campuses, two research centers, and extension offices in every county of the state. TTSU also has a robust online presence with over 90 online programs. TTSU has, on average, a 69\% 6-year graduation rate.

For this study, the researcher utilized secondary data that already exists within the TTSU information system. Data was collected from TTSU's computer information system, known as "Banner," examining demographic, admission, and retention data. The secondary data collected in this survey was not tied to specific students, therefore, the researcher did not have knowledge of individual student admissions records. It would not be possible to associate variables collected to individual students. Approval from TTSU's Institutional Research Board (IRB) was obtained.

The data set for this study is every admitted student to TTSU from fall of 2016, fall of 2017 and fall of 2018. Therefore, this is not a sample of the population but rather includes every admitted and enrolled student for the years mentioned. The total data set includes 12,368 records.

The demographic categorical variables of the study are present in Table One as well as their frequencies. Gender, race, and legacy status are self-submitted by the applicant on the application for admission. Residency refers to their state residency 
status for tuition and fees purposes. Admissions type refers to if the student was automatically admitted through the regular process or if they were admitted by an extended admission process (committee). First-to-second year retention (FSR) refers to if the student re-enrolled the fall quarter after the fall quarter that they were admitted. 
Table 1: Frequency Distributions of the 2016-2018 Freshman Class ( $n=12,368)$ Distributions of 2016-2018 Freshman Class $(n=12,368)$

\begin{tabular}{lcc}
\hline & $\mathrm{N}$ & $\%$ \\
\hline Gender & 6,208 & $50.2 \%$ \\
$\quad$ Female & 6,155 & $49.8 \%$ \\
Male & 5 & $0.0 \%$ \\
$\quad$ Non-Disclosed & & \\
Residency & 3,385 & $24.7 \%$ \\
$\quad$ Non-Resident & 8,983 & $72.6 \%$ \\
$\quad$ Resident & & \\
Admission Type & 10,877 & $87.9 \%$ \\
$\quad$ Automatic & 1,491 & $12.1 \%$ \\
$\quad$ By Committee & & \\
Race $\quad$ & 4,058 & $32.8 \%$ \\
$\quad$ BIPOC & 8,310 & $67.2 \%$ \\
$\quad$ White & & \\
Legacy & 1,732 & $7.81 \%$ \\
$\quad$ Didn't Attend & 9,288 & $41.88 \%$ \\
$\quad$ One or both graduated & 11,156 & $50.31 \%$ \\
$\quad$ Attended - Neither Gradt & & \\
First-to-Second Year Retention & 3,420 & $27.7 \%$ \\
$\quad$ Yes & 8,948 & $72.3 \%$ \\
$\quad$ No & &
\end{tabular}

Note: BIPOC $=$ Black, Indigenous, $($ and) People of Color

Table Two is a summary of the descriptive statistics of the entering freshman class' high school GPA, admissions test scores, and IR scores. The SAT Combined represents the student's SAT test score if they took the SAT or a concatenated SAT score from their ACT score if present (ACT, 2018). Due to the large size of the data population, the distribution of scores demonstrates a normal distribution for generalization purposes (Figures 1-4). 
Table 2: Descriptive Statistics for Test Score and High School GPA

\begin{tabular}{lccccc}
\hline & High School & & & & \\
& GPA & ACT Score & SAT Score & SAT Combined & IR Total Score \\
\hline & & & & & \\
$\mathrm{N}$ & 12,367 & 5,676 & 7,413 & 8,463 & 10,544 \\
Mean & 3.5616 & 24.84 & 1188.90 & 1203.55 & 13.15 \\
SD & 0.39 & 4.44 & 155.13 & 151.42 & 2.22 \\
& & & & & \\
\hline
\end{tabular}

HighSchoolGPA

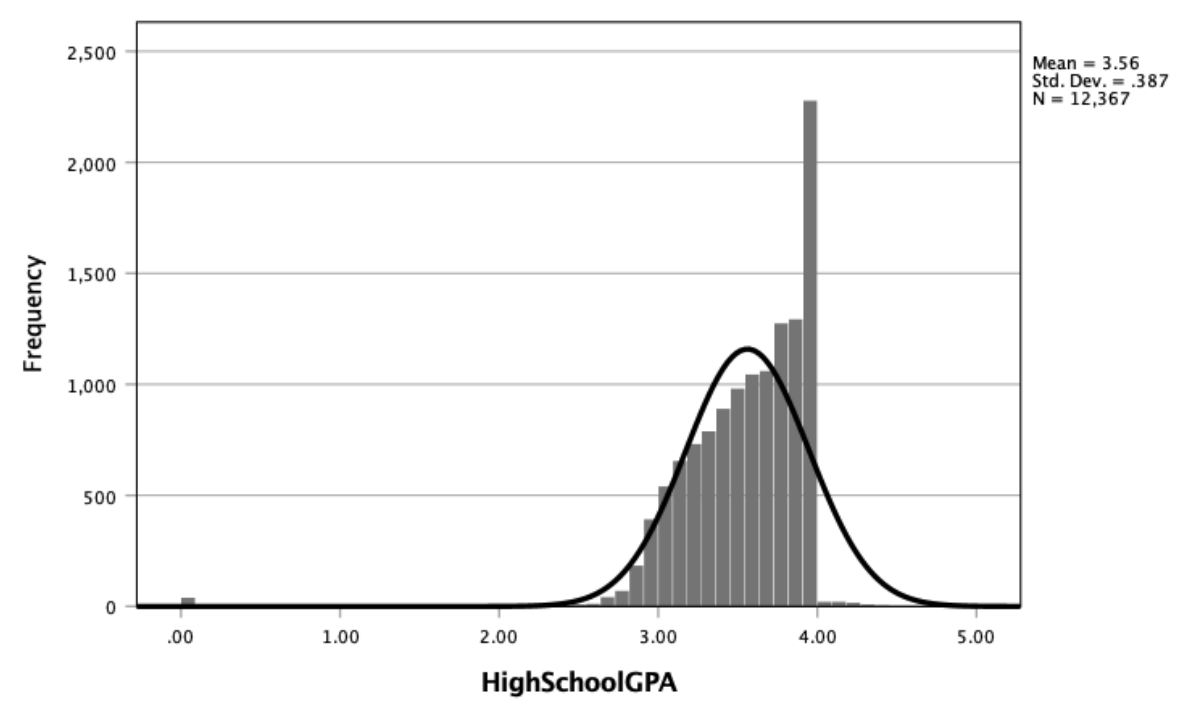

Figure 1: High School GPA Histogram 
ACTCScore

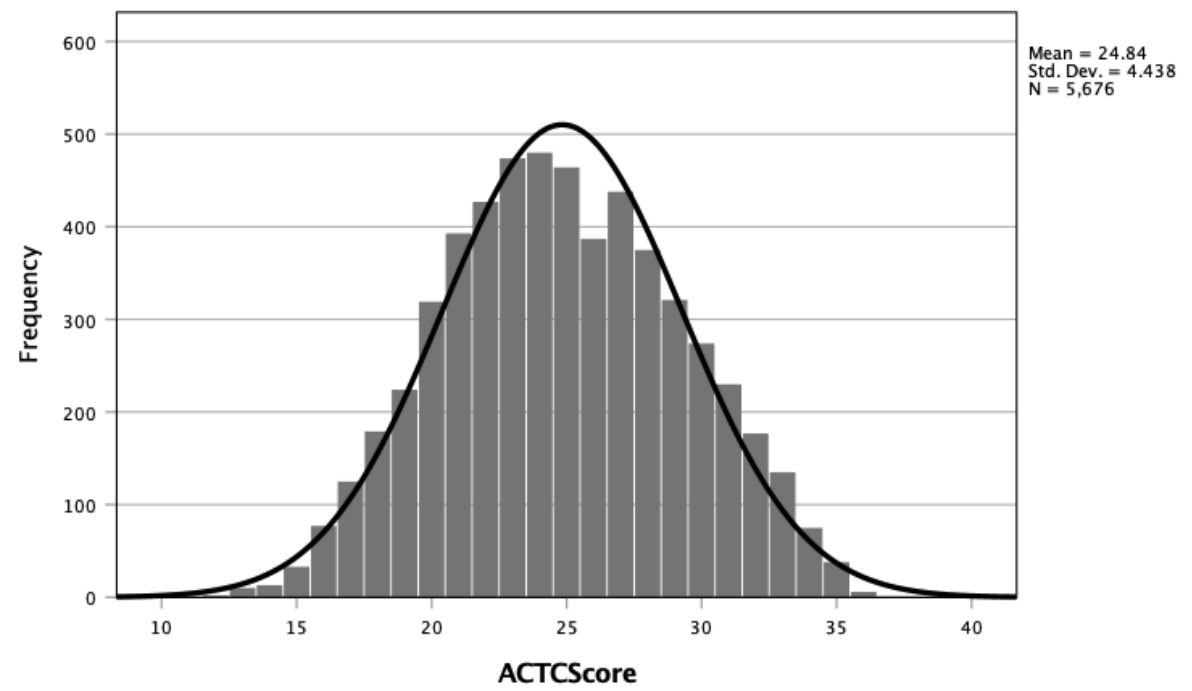

Figure 2: ACT Score Histogram 


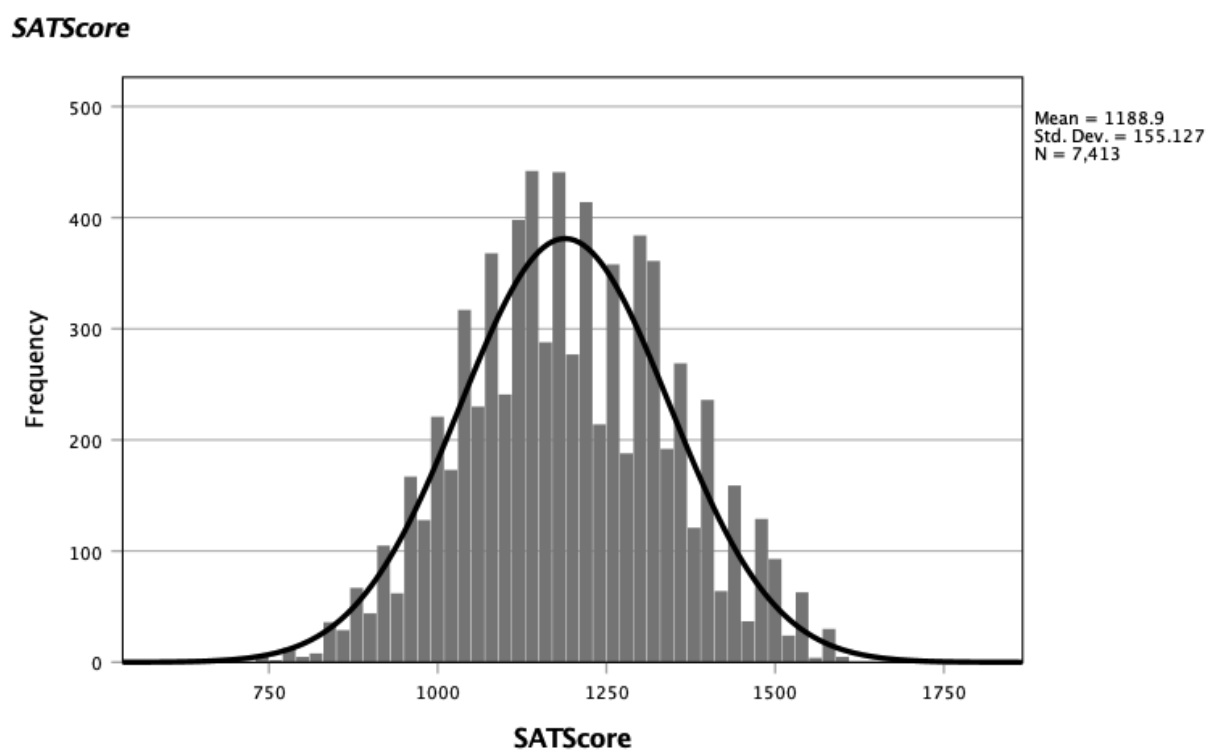

Figure 3: SAT Score Histogram

SATCombined

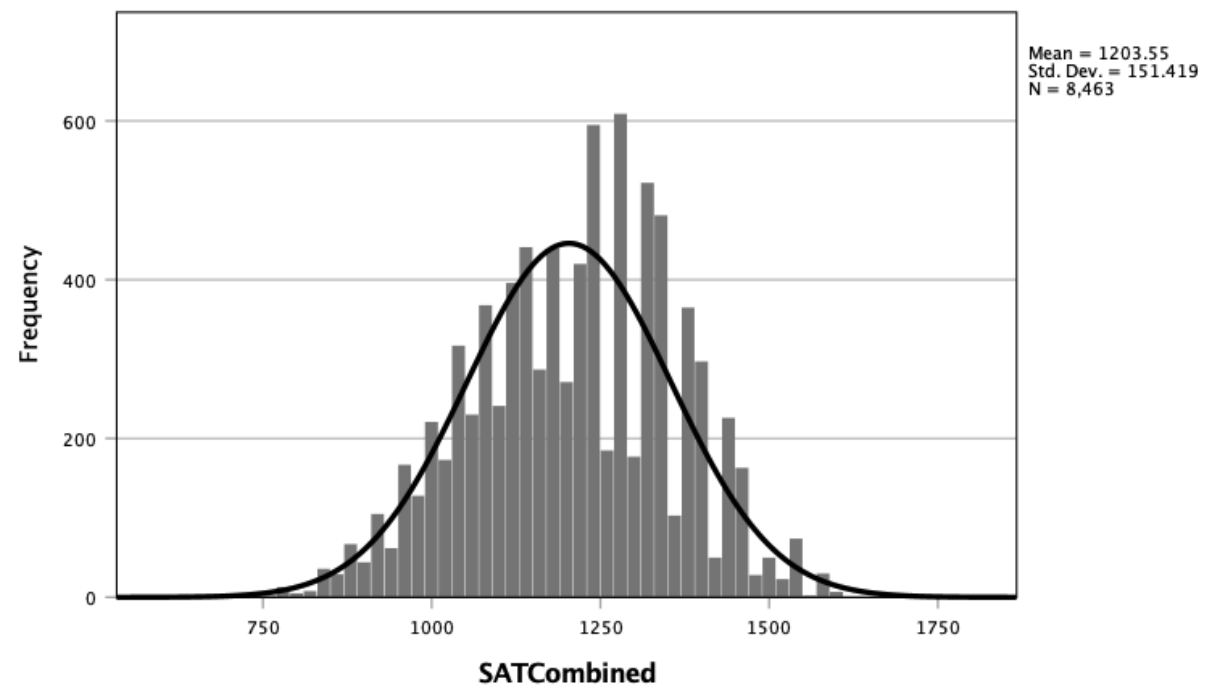

Figure 4: SAT Combined Histogram 


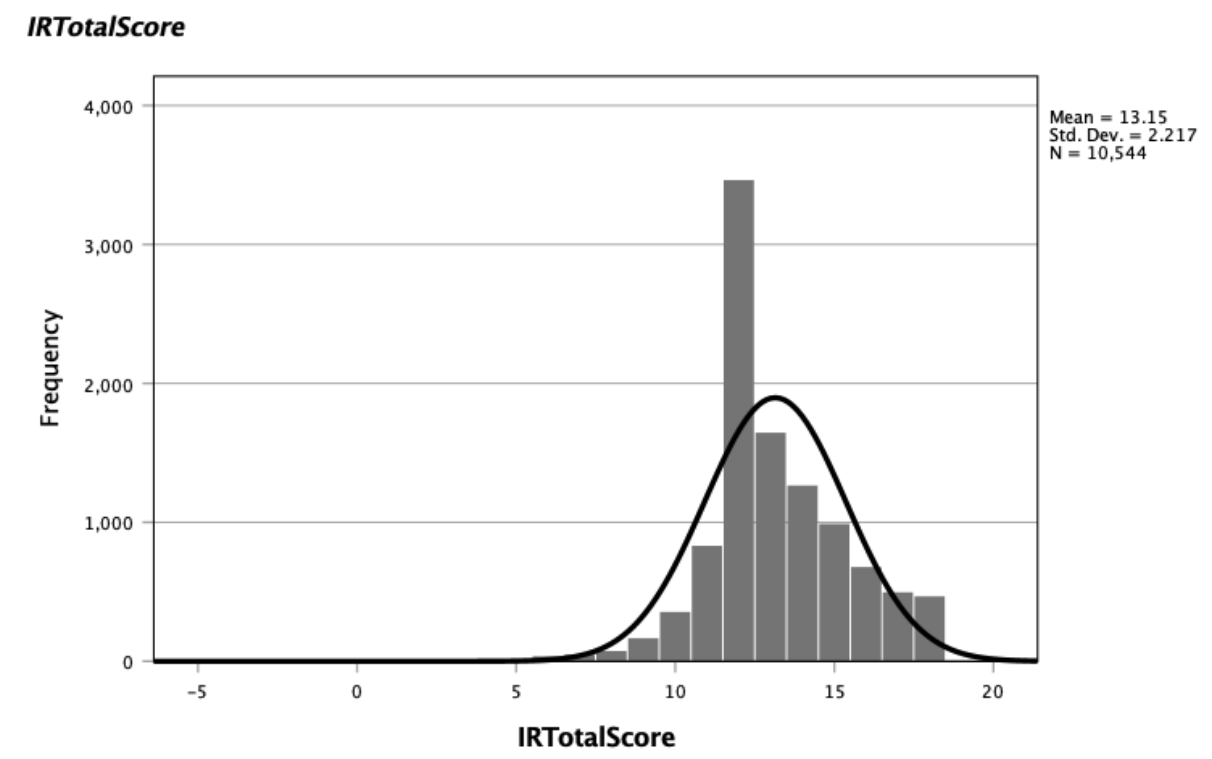

Figure 5: IR Total Score Histogram

The actual first to second year retention rates for the 2016-2018 freshman classes are below (Table 3). Knowing retention rates of participants is helpful context in processing the answers to research questions.

Table 3 First-to-Second Year Retention Rate

\begin{tabular}{|c|c|c|c|c|}
\hline & Fall 2016 & Fall 2017 & Fall 2018 & Total \\
\hline & \multicolumn{4}{|c|}{$\mathrm{N}$} \\
\hline Yes & 2,980 & 2,880 & 2,853 & 8,714 \\
\hline No & 543 & 541 & 488 & 1,571 \\
\hline Total & 3,523 & 3,421 & 3,341 & 10,285 \\
\hline Retention Rate & $84.6 \%$ & $84.2 \%$ & $85.4 \%$ & $84.7 \%$ \\
\hline
\end{tabular}




\section{Procedure}

As an ex-post facto study, the researcher will use multiple descriptive and inferential methods to answer the research questions. All research questions will be tested at the 0.05 significance level. To answer the seven research questions, different types of statistical methods will be used including multiple linear regression and logistic regression. Additionally, both correlation analysis and group means analysis will also be used.

Multiple Linear Regression. As a general statistical technique, multiple regression can be employed to predict values of a particular variable based on knowledge of its association with known values of other variables (Salkind, 2010). Because the bulk of the research questions are looking to predict either admission type and first-to-second year retention, this is the appropriate test to utilize. Simple and multiple regressions were performed in SPSS Statistics for research questions \#1-6. Dummy coding was used for analysis purposes. Dummy Coding means the researcher assigns a binary variable to categories within the regression, as outlined by Salkind and Green (2016).

Prior to testing the significance of variables or combinations of variables, the statistical assumptions were evaluated before reporting of results. As the researcher chose to analyze some of the data using linear regression, a part of that process includes confirming data can legitimately be analyzed with linear regression. This is called "testing for assumptions." There are six assumptions that are checked as a part of this process within SPSS. For this study, none of the regression tests indicated that the 
assumptions of linear relationships, normal distribution of variables, or homogeneity of variance were violated. This is illustrated in Chapter 4 on tables 8-11.

Logistic Regression. Logistic regression is a predictive analysis tool that can be employed when there is a dependent variable that is dichotomous, or binary (Fields, 2009). For the purpose of the study, logistic regression was used to explore the impact of underlying demographics, standardized test scores, admission committee term, Insight Resume scores, and high school GPA on First-to-Second Year Retention by the procedures outlined by Salkind and Green (2016). Logistic regression was used to address research question 7. Additional assumptions of binary logistic regression that were reviewed and met as part of the study including that the variables are linearly related to long odds, minimal co-linerality of independent variables, and large sample sizes typically over 500 (Fields, 2009).

Correlation Analysis. Linear correlation analysis is used as a part of validation procedures. Linear correlation analysis assesses the strength, direction, and association of two variables. Correlation does not infer a cause and effect relationship in substitution of an experimental study which is often inappropriate in educational settings (Salkind, 2010). As a descriptive process, the assumptions that distributions are normally distributed and measures are independent of each other have to be met (Reid, 2013). For this study, the researcher used correlation analysis as a part of research question 7. Specifically, correlation analysis was used to determine the relationship between Insight 
Resume score and high school GPA and test scores that could not be shown through regression linear regression.

Group Means Analysis. A t-test will be used to analyze research questions that assess the differences between BIPOC and white students on a measure. A t-test measures the probability that two groups (or sample from a population) have a systematic difference on a measure beyond chance or error in the measurement (Lavrakas, 2008). An independent t-test as outlined in Salkind and Green (2016) will be employed and the assumptions of independence, normal distribution, and homogeneity of variance have been evaluated and met. This method was utilized as part of answering research question 7 to take a deeper dive into evaluating Insight Resume scores and the demographic of race.

\section{Research limitations}

As with all research, there are limitations to this particular study. In particular, the researcher has decided to use a quantitative approach. Therefore, this phenomenon will be studied from a distance, which means there will be a limited understanding of the full scope of the individual student's experience. Additionally, because of the quantitative approach, the researcher will not be aware of any confounding factors that are not part of the study that may impact a student's first-to-second year retention such as utilization of support services while a student is in attendance at the university. 
The researcher chose to use multiple linear regression to seek outcomes for the majority of the research questions. A potential perspective on the limitation of the research design is the use of linear regression as opposed to logistic regression. The basis of comparison for linear regression is modeled using a straight line whereas logistic regression is the probability of some obtained event of a combination of variables (Green and Salkind, 2017; Salkind and Frey, 2000). Since the dependent variables are related to being automatically admitted to the university or retained from the first-to-second year, the use of logistic regression for all hypotheses would have been a more conventional choice rather than reserved for the final model as a demonstration of the research in practice. While this could be a research limitation, the likelihood is the overall result would have been the same regardless.

Another limitation to this research was the data set itself. While more demographic variables were provided (test scores, veteran status) by TTSU, they were not included in this research due to missing variables between years or lack of variation. The variables that were available within the data set were: Race, gender, age, residency, legacy (one or more parent attended TTSU), test scores, Insight Resume score, first to second year enrollment status, and high school GPA. Given the focus of the literature review and relevance only race, Insight Resume, and first to second year retention status were used in this study. Finally, a research limitation for this study is a de-identified student data set. Because of this, the researcher was not able to track specific data that could give more depth to the findings. For example, the researcher was not able to 
determine if BIPOC students were retained whether or not they were admitted by committee or regular process without connecting specific students to their experience. More research with a smaller identified data set may be able to explore this topic in depth.

\section{Summary}

This chapter discussed research methodologies used for this study. The chapter included a discussion of the overall research philosophy and approach, research strategy, and research procedures. The study utilizes a quantitative method for research and logistic regression to explore the relationship between those numbers. Inductive reasoning was applied to results and will be discussed in depth in Chapter Four. 


\section{Chapter Four: Results}

The purpose of this study is to examine the impacts of non-traditional, noncognitive measures in the college admissions process on retention of academically at-risk student populations. This chapter is organized in sections. Descriptive statistics about the items are first presented, followed by results of each research question.

\section{Descriptive statistics}

Because the research questions relate to admissions type-regular versus committee admissions, Table Four highlights participant data in relation to admissions type. This information breaks down each demographic variable from the data set and shows, by percentage, who was admitted by the regular admissions process versus the committee process for Fall 2016, Fall 2017 and Fall 2018. From this information, we know that females were more likely than males to be admitted by the regular admissions process. It was the same for in-state (resident) students, white identified students, and students who had one or more parents attend and graduate from TTSU. 
Table 4: Participants Break-Down by Admission Type

\begin{tabular}{|c|c|c|c|}
\hline \multicolumn{2}{|c|}{ Regular } & \multicolumn{2}{|c|}{ Committee } \\
\hline $\mathrm{N}$ & $\%$ & $\mathrm{~N}$ & $\%$ \\
\hline \multicolumn{4}{|l|}{$\overline{\text { Gender }}$} \\
\hline Female 5569 & $51.2 \%$ & 639 & $42.9 \%$ \\
\hline Male 5303 & $48.8 \%$ & 852 & $57.1 \%$ \\
\hline \multicolumn{4}{|l|}{ Residency } \\
\hline Non-Resident 2933 & $27.0 \%$ & 452 & $30.3 \%$ \\
\hline Resident 7944 & $73.0 \%$ & 1039 & $69.7 \%$ \\
\hline \multicolumn{4}{|l|}{ Race } \\
\hline BIPOC 3474 & $31.9 \%$ & 584 & $39.2 \%$ \\
\hline White 7403 & $68.1 \%$ & 907 & $60.8 \%$ \\
\hline \multicolumn{4}{|l|}{ Legacy } \\
\hline Didn't Attend 1458 & $13.7 \%$ & 274 & $18.7 \%$ \\
\hline One or both graduated 8199 & $77.0 \%$ & 1029 & $70.4 \%$ \\
\hline Attended - Neither Graduated 997 & $9.4 \%$ & 159 & $10.9 \%$ \\
\hline
\end{tabular}

Because the research questions look at retention rates, Table Five is a breakdown of the whole data set from Fall 2016, Fall 2017, and Fall 2018 and shows retention status based on demographic variables. 
Table 5: Participant Break-Down by Retention Status

\begin{tabular}{|c|c|c|c|c|c|}
\hline & \multicolumn{2}{|c|}{ Retained } & \multicolumn{2}{|c|}{ Not Retained } & \multirow[t]{2}{*}{ Total } \\
\hline & $\mathrm{N}$ & $\%$ & $\mathrm{~N}$ & $\%$ & \\
\hline \multicolumn{6}{|l|}{ Gender } \\
\hline Female & 4442 & $49.6 \%$ & 1766 & $51.7 \%$ & $50.2 \%$ \\
\hline Male & 4505 & $50.4 \%$ & 1650 & $48.3 \%$ & $49.8 \%$ \\
\hline \multicolumn{6}{|l|}{ Residency } \\
\hline Non-Resident & 2344 & $26.2 \%$ & 1041 & $30.4 \%$ & $27.4 \%$ \\
\hline Resident & 6604 & $73.8 \%$ & 2379 & $69.6 \%$ & $72.6 \%$ \\
\hline \multicolumn{6}{|l|}{ Admission Type } \\
\hline Regular & 8035 & $89.8 \%$ & 2842 & $83.1 \%$ & $87.9 \%$ \\
\hline By Committee & 913 & $10.2 \%$ & 578 & $16.9 \%$ & $12.1 \%$ \\
\hline \multicolumn{6}{|l|}{ Race } \\
\hline$B I P O C$ & 2865 & $32.0 \%$ & 1193 & $34.9 \%$ & $32.8 \%$ \\
\hline White & 6083 & $68.0 \%$ & 2227 & $65.1 \%$ & $67.2 \%$ \\
\hline \multicolumn{6}{|l|}{ Legacy } \\
\hline Didn't Attend & 1119 & $12.8 \%$ & 613 & $18.3 \%$ & $14.3 \%$ \\
\hline One or both graduated & 6906 & $78.7 \%$ & 2322 & $69.5 \%$ & $76.2 \%$ \\
\hline Attended - Neither Graduated & 749 & $8.5 \%$ & 407 & $12.2 \%$ & $9.5 \%$ \\
\hline
\end{tabular}

This table shows that for Fall 2016-2018, females were barely retained more than males, resident (in-state) students over out-of-state, students admitted by regular process versus committee process, white students, and students who had one or both of their parents graduate from TSSU.

In addressing the research questions, it was important to first consider admissions type before looking at first to second year retention to determine if it had an impact on retention. This is because the Insight Resume is used in the admission process only for those who are admitted by committee. 
The first three research questions all use admission type (admitted through regular process or by committee) as the dependent variable. Research questions 4-7 focus on first-to-second year retention.

\section{Research Question 1: Underlying Demographic Variables and Admissions Type Analysis}

To answer the first research question of "what underlying demographic variables of admitted students reliably predict admission type (regular versus committee admissions)?" a multiple linear regression was conducted of gender, residency, legacy, and race to determine which measures reliably predict placement into admission type (Table 6). Linear regression was used because the research question asks for a prediction of admission type (regular process v. admission by committee) based on independent demographic variables. Because linear regression was used, the researcher needed to test for assumptions to ensure the data could be analyzed through this process. After testing for assumptions within SPSS, all the underlying demographic variables except for legacy were determined to be a reliable predictor of admission type. Demographic variables of gender, race and residency (in-state versus out-of-state) were all found to have significance in predicting if a student will be admitted by committee or through the traditional admissions process. Legacy status of the student (did their parents attend TTSU) did not have a statistically significant impact on admission type.

In Table Six, the variables are arranged in ascending order, with the top variable representing the variable with the greatest magnitude compared to the rest and the variables. 
Table 6: Regression Analysis Summary for Underlying Demographic Variables Predicting Admission Type

\begin{tabular}{lcccc}
\hline & B & B & $\mathrm{t}$ & $\mathrm{p}$. \\
& & & & \\
(Constant) & 1.101 & & 60.650 & .000 \\
Gender & .038 & .058 & 6.391 & $<.001^{*}$ \\
Race & -.034 & -.048 & -5.276 & $<.001^{*}$ \\
Residency & .017 & .0253 & 2.539 & $.006^{*}$ \\
Legacy & -.001 & .003 & -.332 & .740 \\
\hline
\end{tabular}

Note: ${ }^{*}=$ significant at the .05 alpha level.

Once significant variables were identified (i.e. Gender, race and residency) a multiple linear regression was conducted using these three independent variables (Table 7). The correlations of gender, residency, race and admission category are significant, but very weak. The combination of interaction effects between gender, residency and race explain about $.06 \%$ of the chance of a student being admitted by committee versus regular admission. 
Table 7: Regression Analysis Summary for Demographics Predicting Admission Type

\begin{tabular}{lcccc}
\hline & B & B & t & p. \\
& & & & \\
(Constant) & 1.099 & & 65.292 & .001 \\
Gender & .037 & .057 & 6.381 & $<.001$ \\
& & & & \\
Race & -.034 & -.050 & -5.522 & $<.001$ \\
& & & & \\
Residency & .018 & .025 & 2.081 & .005
\end{tabular}

Note: All variables are significant at the .05 alpha level.

The demographics of race, gender, and residency are significant in predicting admission by regular process versus committee process. White, in-state, female-identified students are more likely to be admitted by the regular admissions process.

\section{Research Question 2: High School GPA, Test Scores, and Admissions Type Analysis}

To answer the second research question "What college admission test scores, high school GPA, and IR test scores of admitted students reliably predict admission type?" a multiple linear regression was conducted for high school GPA, ACT score, SAT score, and Insight Resume total score to determine which measures reliably predict placement into admission type (Table 8). Multiple linear regression was used because the research question asks for a prediction of admission type (regular v. committee) based on independent variables of high school GPA and college admittance test scores. Because 
linear regression was used, the researcher needed to test for assumptions to ensure the data could be analyzed through this process. After testing for assumptions within SPSS, high school GPA was the only reliable predictor of admission type. Those with a higher GPA are more likely to be admitted through the regular admissions process.

Table 8: Regression Analysis Summary for Test Scores and High School GPA Predicting Admission Type

\begin{tabular}{|c|c|c|c|c|}
\hline & B & B & $\mathrm{T}$ & $\mathrm{p}$. \\
\hline (Constant) & 2.859 & & 33.282 & $<.001$ \\
\hline High School GPA & -.446 & -.500 & -28.428 & $<.001 *$ \\
\hline SAT Score & .000 & .174 & 1.382 & .167 \\
\hline ACT Score & .010 & .129 & 1.899 & .058 \\
\hline IR Total Score & .002 & .012 & .702 & .483 \\
\hline
\end{tabular}

Note: $*=$ significant at the .05 alpha level.

A multiple linear regression was conducted with just high school GPA as that is the only variable that was statistically significant (Table 9). The correlation of high school GPA and admission type are moderately correlated. High school GPA explains approximately $17.3 \%$ of the chance of a student being admitted by committee versus regular admission. This means students with higher GPAs are more likely to be admitted 
by the regular admissions process and students with lower GPAs are more likely to be admitted by the admissions committee.

Table 9: Regression Analysis Summary for High School GPA Predicting Admission Type

\begin{tabular}{lcccc}
\hline & B & B & T & p. \\
& & & & \\
(Constant) & 2.369 & & 96.083 & .000 \\
High School GPA & -3.50 & -.416 & -50.931 & .000 \\
\hline
\end{tabular}

High school GPA was found to be a significant predictor in a student being admitted via the regular admissions process versus the committee process. The higher both GPA and test scores, the more likely a student will be admitted by the regular admissions process.

\section{Research Question 3: Demographic Characteristics, High School GPA Analysis, and Admission Type Analysis}

In order to answer the third research question "What underlying combination of college admission test scores, demographic characteristics, high school GPA, and IR scores of admitted students, reliably predict placement admission type?" multiple linear regression was conducted with gender, residency, and race and high school GPA to predict placement by admission type (Table 10). Multiple linear regression was used because the research question asks for a prediction of admission type (regular v. committee) based on independent variables of college admission test scores, demographic characteristics, high school GPA, and Insight Resume scores. These variables were used as they were the most significant in previous regressions. The combination of gender, 
residency, race and high school GPA explains approximately $17.5 \%$ of the chance of a student being admitted by committee versus regular admission. This finding also suggests multiple measures are more effective than single measures in predicting admissions type. Residents who are White and have a higher high school GPA are more likely to be admitted via the regular admissions process.

Even though gender is no longer a significant contributor to the model, removing gender from the model didn't improve the shared variance and so was retained in the final model. The final model will be used to answer research question 7. 
Table 10: Regression Analysis Summary for Demographics and High School GPA Predicting Admission Type

\begin{tabular}{lcccc}
\hline & B & B & T & p. \\
& & & & \\
(Constant) & 2.450 & & 77.793 & .000 \\
High School GPA & -.351 & -.417 & -50.251 & $.000^{*}$ \\
& & & & \\
Race & & & & \\
Residency & -.022 & -.032 & -3.878 & $<.001^{*}$ \\
Gender & -.016 & -.022 & -2.633 & $.008^{*}$ \\
& & & & \\
& .002 & .003 & .386 & .699 \\
\hline
\end{tabular}

Note: $*=$ significant at the .05 alpha level.

High school GPA, race and residency status (in-state versus out-if-state) are significant predictors if a student will be admitted by the regular admission process versus admission by committee. White, in-state students with higher GPAs are more likely to be admitted by the regular admissions process.

\section{Research Question 4: Demographic Variables, Admission Type and First-to-Second First Year Retention Analysis}

To address the fourth research question "What underlying demographic variables of admitted students and admissions type reliably predict first-to-second year retention of freshman students?" A multiple linear regression was conducted for gender, residency, legacy, race and admission decision type to determine which measures reliably predict first to second year retention of first-year students (Table 11). Multiple linear regression 
was used because the research question asks for a prediction of first to second year retention based on independent variables including demographics and admission type. Because linear regression was used, the researcher needed to test for assumptions to ensure the data could be analyzed through this process. After testing for assumptions within SPSS, gender, residency, and admission decision type were determined to be reliable a predictor of first-to-second year retention. This means if a student is admitted through the regular process (i.e. not committee) and is retained, they are more likely male and an in-state student. In terms of impact or significance, admission type contributes most to predicting first-to-second year retention, followed by residency and gender, respectively. 
Table 11: Regression Analysis Summary for Demographics, Admission Type in Predicting First-to-Second Year Retention

\begin{tabular}{lcccc}
\hline & B & B & $\mathrm{t}$ & $\mathrm{p}$. \\
& & & & \\
\hline (Constant) & 1.156 & & 40.318 & .000 \\
Admission Type & .128 & .093 & 10.254 & $<.001^{*}$ \\
Residency & .035 & .035 & 3.796 & $<.001^{*}$ \\
Race & -.020 & -.020 & -2.244 & $.025^{*}$ \\
Gender & -.016 & -.018 & -2.018 & $.044^{*}$ \\
Legacy & .008 & .012 & 1.351 & .177 \\
\hline
\end{tabular}

Note: $*=$ significant at the .05 alpha level.

A multiple linear regression was conducted on the variables that were shown to be statistically significant (i.e. admission type, residency, race and gender) (Table 12). Multiple linear regression was used because the research question was asking for a prediction of first to second year retention based on independent variables of admission type, residency, race and gender. The correlations of admission type, residency, race and gender are significant in considering first to second year retention. This means those admitted by regular admission process, in-state, White, and identify as male are most likely to be retained. The combination of admission type, residency, race and gender explain approximately $1.1 \%$ of the chance of persisting to the second year. 
Table 12: Multiple Linear Regression Analysis for Demographics Predicting First-toSecond Year Retention

\begin{tabular}{lcccc}
\hline & B & B & $\mathrm{t}$ & $\mathrm{p}$. \\
& & & & \\
\hline (Constant) & 1.146 & & 42.885 & .000 \\
Admission Type & .126 & .091 & 10.186 & $<.001$ \\
Residency & .037 & .037 & 4.157 & $<.001$ \\
Gender & -.018 & -.020 & -2.253 & .024 \\
Race & -.019 & -.020 & -2.202 & .028 \\
\hline
\end{tabular}

Note: All variables are significant at the .05 alpha level.

The demographics of admission type, residency, race and gender are significant in predicting first-to-second year retention. Students admitted by regular admission, in-state, white and male-identified are more likely to be retained.

\section{Research Question 5: Analysis of High School GPA, Admissions Test Scores, and IR Scores for Admitted Students in Predicting First-to-Second Year Retention}

To answer the fifth research question "What college admission test scores, high school GPA, and IR test scores of admitted students predict first-to-second year retention of freshman students?" a multiple linear regression was conducted for high school GPA, test scores and Insight Resume score to determine which measures reliably predict first to second year retention of first-year students (Table 13). Multiple linear regression was used because the research question asks for a prediction of first to second year retention 
based on independent variables of test scores, high school GPA and Insight Resume score. Because linear regression was used, the researcher needed to test for assumptions to ensure the data could be analyzed through this process. After testing for assumptions within SPSS, high school GPA and test scores were determined to be reliable a predictor of first-to-second year retention. The Insight Resume score was not statistically significant in predicting first to second year retention as a single predictive measure.

Table 13: Regression Analysis Summary for High School GPA, Test Scores, and IR Scores to Predict First-to-Second Year Retention

\begin{tabular}{lcccc}
\hline & B & B & T & p. \\
& & & & \\
(Constant) & 2.411 & & 21.494 & $<.001$ \\
SAT Score & -.001 & -.278 & -3.833 & $<.001^{*}$ \\
High School GPA & -.171 & -.150 & -7.576 & $<.001^{*}$ \\
ACT Score & & & & \\
IR Score & -.013 & .007 & 1.905 & .057 \\
& & & & \\
& .003 & .004 & .016 & .384 \\
\hline
\end{tabular}

Note: *= significant at the .05 alpha level.

A multiple linear regression was conducted on the variables that were determined to be significant: SAT Score and high school GPA (Table 14). For admission test scores, the concatenated test scores (SAT Combined) was utilized. The correlations of high school GPA and SAT Combined scores are significant in predicting first to second year 
retention. The combination of SAT combined scores and high school GPA explain approximately $6.1 \%$ of the chance of persisting to the second year.

Table 14: Multiple Linear Regression for High School GPA and SAT Combine in Predicting First-to-Second Year Retention

\begin{tabular}{lcccc}
\hline & B & B & T & p. \\
& & & & \\
\hline (Constant) & 2.394 & & 47.454 & .000 \\
SAT Combined & -.001 & -.190 & -17.135 & $<.001$
\end{tabular}

$\begin{array}{lllll}\text { High School GPA } & -.127 & .013 & -9.889 & <.001\end{array}$

Note: Both variables are significant at the .05 alpha level.

SAT combined scores and high school GPA are significant predictors of first-to-second year retention. The higher both the test score and GPA, the more likely a student is to be retained.

Research Question 6: Analysis of College Admission Test Scores, Demographic Characteristics, High School GPA, and IR Scores in Predicting First-to-Second Year Retention

To address the sixth research question "What underlying combination of demographic variables, admission type, high school GPA, and Insight Resume scores reliably predict first-to-second year retention of freshman students?" a multiple linear regression was conducted for test scores, demographic characteristics, and high school GPA to determine which measures reliably predict first to second year retention of first- 
year students (Table 15). Multiple linear regression was used because the research question asks for a prediction of first to second year retention based on independent variables of demographics, admission type, high school GPA and Insight Resume score. Because multiple linear regression was used, the researcher needed to test for assumptions to ensure the data could be analyzed through this process. After testing for assumptions within SPSS, high school GPA, test scores and admission type (regular admission $\mathrm{v}$. admission by committee) were determined to be a significant predictor of first to second year retention. This means a higher high school GPA, higher test scores, and regular admission is most likely to predict first to second year retention. The combination of admission type, SAT combined test score, and high school GPA explains approximately $6.2 \%$ of first to second year retention. Since removal of the underlying demographic variables didn't impact the shared variance in the model, all variables are retained in the final regression. 
Table 15: Regression Analysis Summary for SAT Combined Test Scores, Demographic Characteristics, IR Scores, Admission Type and High School GPA to Predict First-toSecond Year Retention

\begin{tabular}{lcccc}
\hline & B & B & t & p. \\
& & & & \\
\hline (Constant) & 2.234 & & 32.616 & $<.001$ \\
SAT Combined & -.001 & -.190 & -16.564 & $<.001^{*}$ \\
High School GPA & -.105 & -.091 & -7.295 & $<.001^{*}$ \\
Admission Type & .054 & .039 & 3.311 & $<.001^{*}$ \\
Residency & .018 & .018 & 1.724 & .085 \\
Race & & & & .996 \\
Gender & .0001 & .000 & -.005 & .996 \\
\hline
\end{tabular}

Note: $*=$ significant at the .05 alpha level.

SAT combined test score, high school GPA, and admission type are a significant predictor of first-to-second year retention. A student with higher test scores and GPAs, along with admission by the regular process, is more likely to lead to student retention.

A simple linear regression was conducted to determine if Insight Resume score can solely reliably determine first to second year retention (Table 16). Linear regression was used because the research question was asking for a prediction of first to second year retention based on the independent variable. Insight Resume score alone was determined to not be a reliable predictor of first-to-second year retention. 
Table 16: Regression Analysis Summary for Insight Resume Score to Predict First-toSecond Year Retention

\begin{tabular}{lcccc}
\hline & B & B & t & p. \\
& & & & \\
\hline (Constant) & 1.274 & & 49.534 & .000 \\
& & & & \\
IR Total Score & -.001 & -.005 & -5.26 & .599 \\
& & & & \\
\hline
\end{tabular}

Insight resume alone is not a significant predictor of first-to-second year retention.

A multiple linear regression was conducted for relevant demographic

characteristics, high school GPA, combined SAT test scores and Insight Resume score to determine which measures reliably predict first to second year retention of first-year students (Table 17). Multiple linear regression was used because the research question was asking for a prediction of first to second year retention based on independent variables of demographic characteristics, high school GPA, combined SAT test scores and Insight Resume score. These variables were chosen as they had all shown previous statistical significance in predicting first to second year retention. Because multiple linear regression was used, the researcher needed to test for assumptions to ensure the data could be analyzed through this process. After testing for assumptions within SPSS, high school GPA, test scores, admission type and residency were determined to be reliable predictors of first-to-second year retention. Therefore, in-state students with a higher GPA, higher test scores, and admissions by regular committee are most likely to be 
retained. The combination of high school GPA and test scores explain approximately $6.6 \%$ of the chance of persisting to the second year.

Table 17: Linear Regression Analysis Summary for SAT Combines Test Scores, Demographic Characteristics, IR Scores and High School GPA to Predict First-toSecond Year Retention

\begin{tabular}{lcccc}
\hline & B & B & T & p. \\
& & & & \\
\hline (Constant) & 2.185 & & 27.361 & $<.001$ \\
SAT Score Combined & .000 & .041 & 3.172 & $.002^{*}$ \\
High School GPA & -.126 & -.114 & -8.261 & $<.001^{*}$ \\
Admission Type & .053 & .041 & 3.172 & $.002^{*}$ \\
Residency & .023 & .023 & 1.994 & $.046^{*}$ \\
IR Score & .003 & .017 & 1.465 & .143 \\
Race & -.005 & -.006 & -.481 & .630 \\
Gender & -.004 & -.005 & -4.03 & .687 \\
& & & & \\
\hline
\end{tabular}

Note: $*=$ significant at the .05 alpha level.

To determine if the Insight Resume total score was negatively impacting the predictive validity, a linear regression was conducted with variables above except the Insight Resume total score (Table 18). The combination of combined SAT score, high school GPA, admission type, and residency explain approximately $6.2 \%$ of the chance of 
persisting to the second year. Removal of IR score also impacted the predictive validity of residency and admissions type (Table 18).

Table 18: Linear Regression Analysis Summary for SAT Combines Test Scores, Demographic Characteristics and High School GPA to Predict First-to-Second Year Retention

\begin{tabular}{lcccc}
\hline & B & B & $\mathrm{t}$ & $\mathrm{p}$. \\
\hline (Constant) & 2.234 & & 32.017 & $<.001$ \\
SAT Combined & -.001 & -.190 & -16.564 & $<.001^{*}$ \\
High School GPA & -.105 & -.091 & -7.295 & $<.001^{*}$ \\
Admissions Type & .054 & .039 & 3.311 & $<.001^{*}$ \\
Residency & .018 & .018 & 1.724 & .085 \\
Race & $<.0001$ & .000 & -.005 & .996 \\
Gender & .000 & .000 & -.025 & .980 \\
\hline
\end{tabular}

Note: $*=$ significant at the .05 alpha level.

To determine if the combination of Insight Resume total score and gender were negatively impacting the predictive validity, linear regressions were conducted with variables in Table 14 without gender and race (Table 15). SAT combined test score, high school GPA and admissions type explains approximately $6.2 \%$ of the chance of persisting to the second year. Since the model in Table 18 explains the most shared variance, this 
model will be retained as the final model. The final model will be used to help us explore the final research question.

\section{Research Question 7: Analysis of Predictive Validity in First-to-Second Year Retention}

To address the final research question "To what extent do the underlying combination of college admission test scores, admission type, demographic characteristics, high school GPA, and Insight Resume scores reliably predict first-tosecond year retention of freshman students?" a logistic regression was performed to ascertain the effects of gender, race, residency, admission type, Insight Resume score, high school GPA, and SAT combined score on the likelihood that a first year student would persist to the second year. The logistic regression model was statistically significant, $\chi 2(6)=533.26, \mathrm{p}<.001$. The model explained $8.8 \%$ of the variance in firstto-second year retention and correctly classified $72.9 \%$ of cases (Tables 19 and 20). Table 19 demonstrates that admission type is the greatest influence in predicting first to second year retention. Table 19 also indicates the amount of predictive validity that each variable contains given all other variables being equal even if the variable is a not significant predictor of retention as a single measure. 
Table 19: Logistics Regression to Demonstrate Effects of Demographics, Admission Type, IR Score, High School GPA and SAT Combined on First to Second Year Retention

\begin{tabular}{lllllllll}
\hline & $\mathrm{B}$ & S.E. & Wald & df & Sig. & $\operatorname{Exp}(\mathrm{B})$ & $\mathrm{R}^{2 \mathrm{a}}$ & Positive Factor \\
\hline Constant & 4.993 & 0.487 & 105.23 & 1 & $<0.001 *$ & 147.39 & $\mathrm{NA}$ & \\
IR Score & 0.019 & 0.013 & 2.01 & 1 & 0.156 & 1.02 & $1,300 \%$ & 1 point increase \\
Residency & 0.103 & 0.063 & 2.62 & 1 & 0.105 & 1.11 & $10.30 \%$ Resident \\
Admission Type & 0.094 & 0.089 & 1.1 & 1 & 0.294 & 1.11 & $9.40 \%$ & Regular \\
Gender & 0.052 & 0.061 & 0.75 & 1 & 0.386 & 0.95 & $5.20 \%$ & Male \\
& & & & & & & & .05 point \\
High School GPA & 0.970 & 0.104 & 86.92 & 1 & $<0.001 *$ & 0.38 & $3.00 \%$ & increase \\
SAT Score & & & & & & & & 10 Point \\
Combined & $0.003<.001$ & 140.53 & 1 & $<0.001 *$ & 1.00 & $3.00 \%$ & Increase \\
Race & 0.022 & 0.061 & 0.13 & 1 & 0.72 & 0.98 & $2.20 \%$ & White \\
\hline
\end{tabular}

Note: ${ }^{a} \mathrm{R}^{2}$ represents the positive increase in predictive retention based on the positive facto and all variables remaining the same.

*= significant at the .05 alpha level.

Table 19 explains that resident students admitted by the regular admission process, maleidentified, and white are more likely to be retained. It also explains correlation between increases in Insight Resume score, higher GPA and higher test scores in relation to firstto-second year retention. For example, a resident student is $10 \%$ more likely to be retained versus a non-resident student if all other variables (i.e. the same Insight Resume score, admission type, gender, race, GPA and test scores) are the same. This table also demonstrates how higher GPA and test scores impact retention. For example, a .05 higher GPA increase predicted retention by $4 \%$ if all other variables are the same. A 10 -point increase in SAT combined test score increases predicted retention by $3 \%$ if all other variables are the same. 
While a predictive model was not something that was set out to be achieved during the initial proposal, a model of predicting retention began to take shape. Table 19 illustrates the basis of the predictive model that was uncovered through this research to predict retention. More information about this model is in the following section on posthoc analysis.

Table 20: Logistic Regression Classification Table for First-to-Second Year Retention

\begin{tabular}{|c|c|c|}
\hline & Predicted & \multirow[t]{2}{*}{ Percentage Correct } \\
\hline & Yes No & \\
\hline Yes & 6,002166 & 97.3 \\
\hline Observed No & 2,114151 & $6.60 \%$ \\
\hline Overall Percent & & $72.70 \%$ \\
\hline
\end{tabular}

Table 20 reflects the percentage of times the predictive model was correct in determining first-to-second year retention based on variables. This means that the model will "get it right" in predicting who will be retained almost $73 \%$ of the time. 


\section{Post-Hoc Analyses}

After the initial research questions were answered, the researcher wanted to explore the relationship between some of these variables further. In particular, take a deeper look in to relationships between variables of admission type, Insight Resume scores to see if there was information that could lead to predictive factors for retention. The initial research questions did not fully answer how these all might work together to predict retention and so more tests were conducted. The information on these is shared below.

Predictive validity of admission type on first to second year retention. Even though admissions type was determined to be a significant predictor of first-to-second year retention in a previous model, a simple linear regression was conducted to determine significance of admissions type alone on first to second year retention. It is shown, again, to be a significant predictor of first to second year retention (Table 21). Admissions type (admitted by regular process v. committee process) explains approximately .08\% of the chance of persisting to the second year. 
Table 21: Regression to Predict Impact of Admissions Type on First to Second Year Retention

\begin{tabular}{lccccc}
\hline & B & B & T & p. \\
& & & & \\
\hline (Constant) & 1.135 & & 76.069 & .000 \\
& & & & \\
Admissions Type & .126 & .092 & 10.274 & $<.001$ \\
\hline
\end{tabular}

Correlational analysis was conducted to determine if the IR scores had a linear relationship with high school GPA, ACT scores, and SAT scores (Table 22). A linear relationship is used to describe phenomenon, or, looking at past events to try and predict future events. (Salkin, N., 2000) Results of the Pearson correlation indicate that there was a moderate correlation between high school GPA, ACT score, SAT score, or combined SAT where the range of the variance of High School GPA can be explained by $8.89 \%$ $9.49 \%$ of the variance in standardized test scores. In other words, we can predict up to 8$9 \%$ of change in one variable based on the other variable.

IR scores indicate a very weak positive association with all measures. Since the magnitude of the significant correlation is essentially zero for high school GPA and Insight Resume scores, the significance is likely due to the ability to detect significant differences due to the large sample size. Approximately $0.03-0.10 \%$ of the variation in Insight Resume scores can be explained by the variation in standardized test scores. 
Table 22: Pearson Correlation Coefficients for High School GPA, Standardized Test Scores, and IR Total Scores

\begin{tabular}{lccccc}
\hline & $\begin{array}{c}\text { High School } \\
\text { GPA }\end{array}$ & $\begin{array}{c}\text { ACTC } \\
\text { Score }\end{array}$ & $\begin{array}{c}\text { SAT } \\
\text { Score }\end{array}$ & $\begin{array}{c}\text { SAT } \\
\text { Combined }\end{array}$ & $\begin{array}{c}\text { IR Total } \\
\text { Score }\end{array}$ \\
\hline $\begin{array}{l}\text { High School } \\
\text { GPA }\end{array}$ & 1 & $.372^{*}$ & $.376^{*}$ & $.382^{*}$ & $0.03^{*}$ \\
ACTC Score & $.372^{*}$ & 1 & $.967^{*}$ & $.975^{*}$ & $.032^{*}$ \\
SAT Score & $.376^{*}$ & $.967^{*}$ & 1 & $.995^{*}$ & $.032^{*}$ \\
SAT Combined & $.382^{*}$ & $.975^{*}$ & $.995^{*}$ & 1 & $.057^{*}$ \\
IR Total Score & $0.03^{*}$ & $.032^{*}$ & $.032^{*}$ & $.057^{*}$ & 1 \\
\hline
\end{tabular}

Note: $*=$ significant at the .05 alpha level.

Scatter Plot of SAT Score by High School GPA

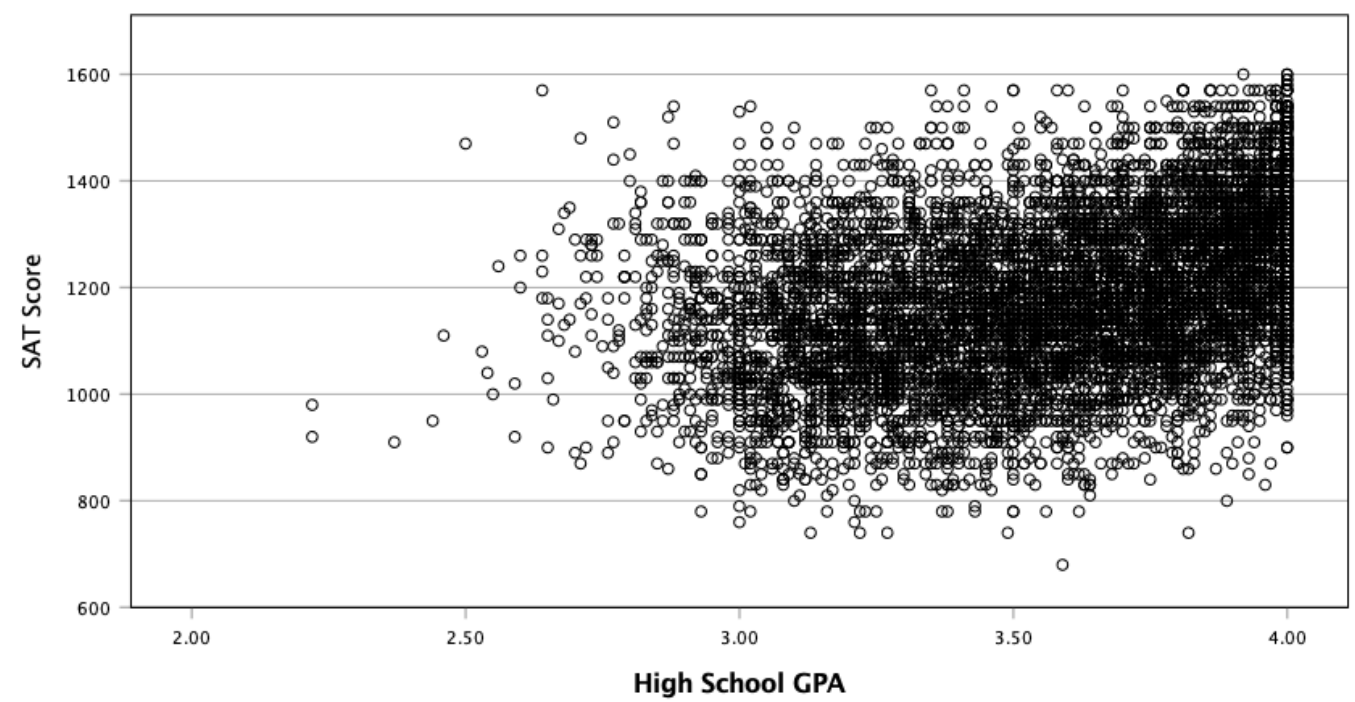

Figure 6: Combined SAT Score and High School GPA Scatter Plot 
Scatter Plot of IR Score by High School GPA

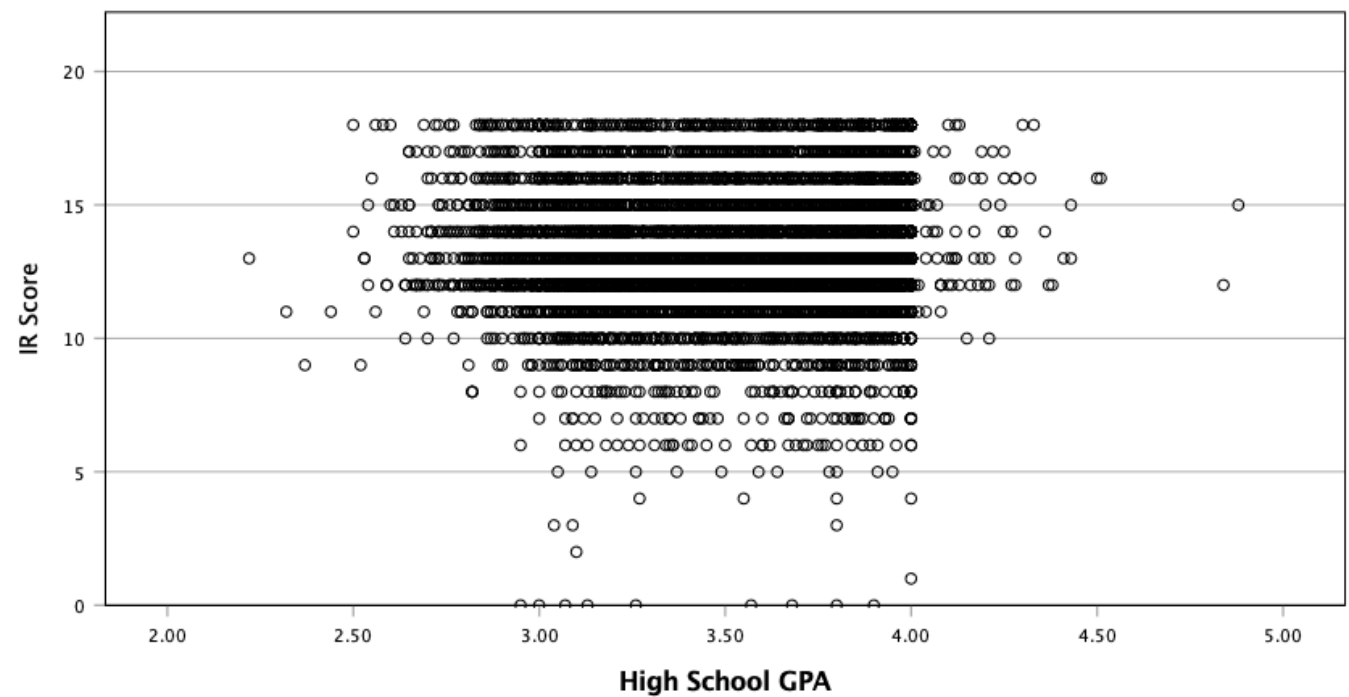

Figure 7: IR Total Score and High School GPA Scatter Plot

Scatter Plot of SATScore by IRTotalScore

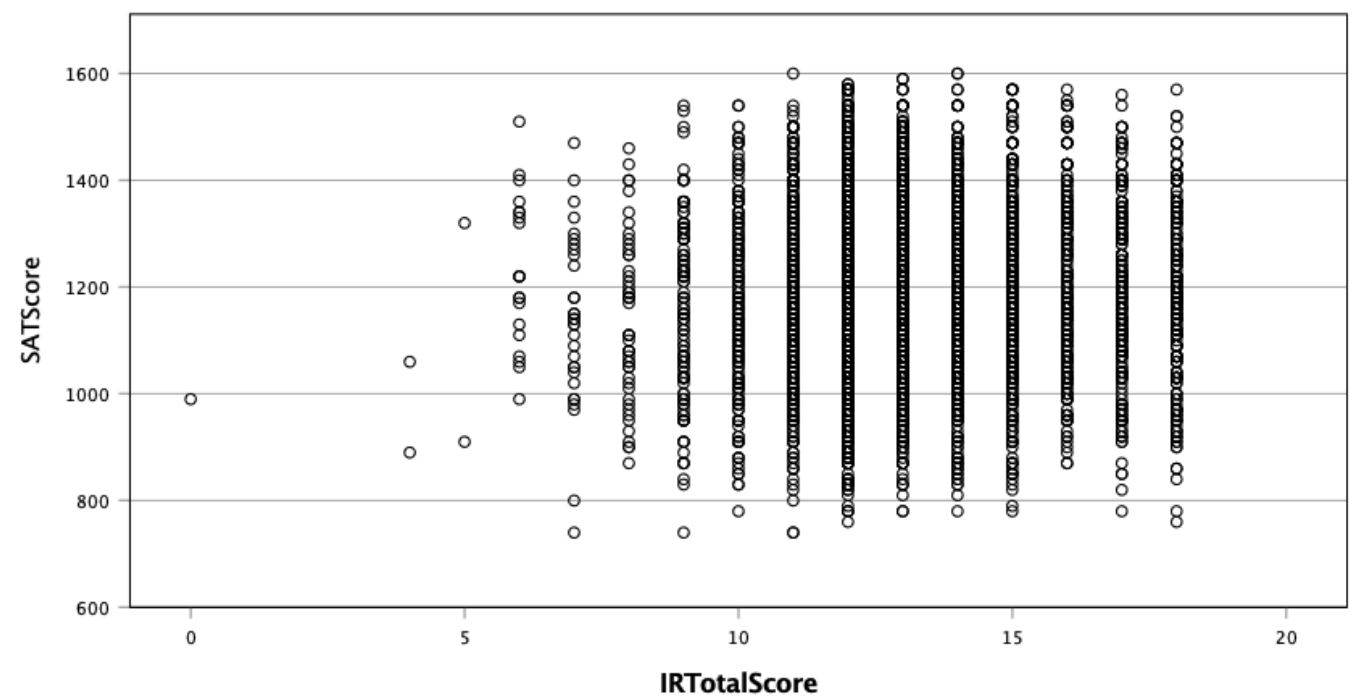

Figure 8: Combined SAT Score and IR Total Score Scatter Plot 


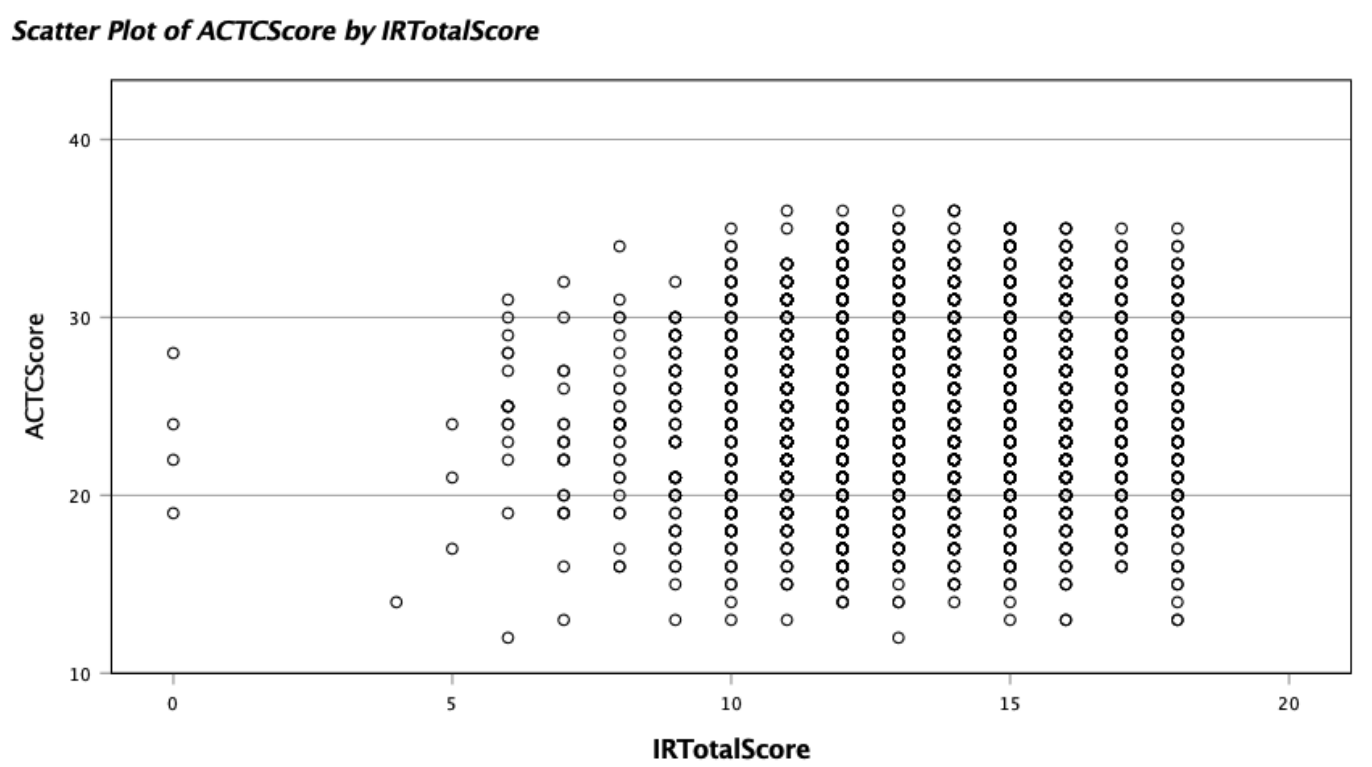

Figure 9: ACT Score and IR Total Score Scatter Plot

Analysis of Insight Resume scores and race. As the researcher continued to explore more in depth what variables predict retention and how, an independent t-test was conducted to evaluate if Insight Resume Scores differed between BIPOC and White firsttime freshman. Even though white students score higher on average on the Insight Resume score than BIPOC students (Table 23), the test was not significant $t(10,542)=$ $0.80, p=2.13$ suggesting that any variation was due to chance or error in the measurement. 
Table 23: Demographic Summary of IR Test Scores by Race

\begin{tabular}{cccc}
\hline & $\mathrm{N}$ & Mean & Std. Deviation \\
\hline BIPOC & 3362 & 13.12 & 2.22 \\
& & & \\
White & 7182 & 13.16 & 2.22 \\
\hline
\end{tabular}

Analysis of First to Second Year Retention and Race. A linear regression was conducted for the demographic category of race to predict first to second year retention (Table 24). Race was a significant predictor in first to second year retention. Race explains approximately $.01 \%$ of the chance of persisting to the second year. This means White students are more likely to be retained than BIPOC students.

Table 24: Linear Regression for Demographic of Race and First to Second Year Retention

\begin{tabular}{lcccc}
\hline & B & B & T & p. \\
\hline (Constant) & 1.312 & & $88.763<0.01$ \\
Race & -0.026 & -0.027 & $-3.036<0.01$ \\
\hline
\end{tabular}

This finding means that White students are more likely to persist at TTSU.

\section{Predictive Model}

While not the original intention of this research, the size of the data set combined with the information that was uncovered led the researcher to develop a predictive model for first-to-second year retention. The final predictive model based on this research is as follows: 
Retention Score $=4.993+0.019($ IR Score $)+0.103($ Residency $)+0.094($ Admission Type $)$ +0.052 (Gender) +0.980(High School GPA) +0.003 (SAT Combined) + 0.022(Race).

These numbers are based on the beta values from Table 19. This means one can use these numbers to compare the strength of the effect of each independent variable i.e. test score, GPA, demographics) to the dependent variable (retention) and where the dummy coding (as discussed previously) for the categorical variables are:

- Residency: 1=Non-Resident, 2=Resident;

- Admission Type: $1=$ Committee, $2=$ Automatic;

- Gender: 1=Female, 2=Male; and

- $\quad$ Race: 1=BIPOC 2=White.

By using data reported to the institution by the student, this model produces a retention score for each student that is effective for predicting first-to-second year retention rates due to the use of multiple variables and taking into consideration their unique contributions to the retention of the student population that was used from this data set. Implications for this predictive model are discussed further in Chapter 5.

\section{Summary}

The researcher used descriptive statistics, group means analysis, linear and logistic regression to examine if the use of non-traditional admissions procedures like the Insight Resume has an impact on admission to college and first-to-second year retention of freshman students. After analyzing underlying demographic characteristics, the combination of standardized test scores, high school GPA, ACT, gender and race were 
determined to be reliably predictors of first to second year retention. In-state, male, White students with higher test scores and higher GPA's are more likely to persist. When used as a sole variable the Insight Resume does not have predictive value for first to second year retention, but when combined with other variables the predictive value for first to second year retention can increase.

After all research questions were answered, the researcher wanted to explore more in-depth relations between variables that would explain what, exactly, might be a predictor of first to second year retention. A predictive model was established in order to consider how variables might impact first-to-second year retention. This model considers how demographic variables impact retention. It also considers how increases in GPA and test score could have a positive impact on retention. The model was able to correctly predict persistence to the 2 nd year $72.7 \%$ of the time. 


\section{Chapter Five: Summary}

Increasing access to higher education is of benefit to individuals and society as a whole, and effective in addressing health and economic disparities. Therefore, reviewing traditional college admissions criteria is critical for increasing access and student achievement inherent in most institutional missions.

This study focused on admission and retention of first-year college students who are academically at-risk based on being admitted to a university through an extended admissions process (admitted by committee). This means they are starting their university career with a GPA less than 3.0, lower test scores, and/or missing required preparatory classes. An exploratory quantitative study was conducted to consider what predictive traits could be identified.

The purpose of this study is to examine the impacts of non-cognitive measures in the college admissions process on retention of academically at-risk student populations. This chapter discusses the results of this study. In addition, this chapter also provides suggestions for further areas of study.

In this study, the researcher used an exploratory quantitative process to answer the following questions:

1. What underlying demographic variables of admitted students reliably predict admission type?

2. What college admission test scores, high school GPA, and Insight Resume test scores of admitted students reliably predict admission type? 
3. What underlying combination of college admission test scores, demographic characteristics, high school GPA, and Insight Resume scores of admitted students, reliably predict placement admission type?

4. What underlying demographic variables of admitted students and admissions type reliably predict first-to-second year retention of freshman students?

5. What college admission test scores, high school GPA, and Insight Resume test scores of admitted students predict first-to-second year retention of freshman students?

6. What underlying combination of demographic variables, admission type, high school GPA, and IR scores reliably predict first-to-second year retention of freshman students?

7. To what extent do the underlying combination of college admission test scores, admission type, demographic characteristics, high school GPA, and Insight Resume scores reliably predict first-to-second year retention of freshman students?

To answer these questions, the researcher used descriptive statistics, group means analysis, linear and logistic regression to examine if the use of non-traditional admissions procedures like the Insight Resume has an impact on admissions and first to second year retention of incoming college students. Limitations of the study are suggested through the chapter. 


\section{Summary of Findings}

Three of the research questions in this study focused on prediction of admission type (regular process or by committee) and four research questions focused on first-tosecond year retention.

Demographic variables of gender, race, residency (in-state versus out-of-state) were found to have significance in predicting admissions type while legacy (did their parents attend TTSU) did not. The researcher also tested high school GPA, ACT score, SAT score, and IR total score to determine which measures reliably predict placement into admission type (i.e. admitted by regular process versus by committee process.) High school GPA was the only reliable predictor of admission type from this grouping. Given what is known about the TTSU admission process, this result was not surprising. A low high school GPA would be more likely to be admitted by committee as those who do not meet admission requirements of 3.0 or above must be admitted by committee.

In considering the combination of demographic types and college admission test scores, high school GPA, and Insight Resume scores of admitted students the most significant predictors for admission type overall were high school GPA, race and residency. Based on the data set from Fall 2016-Fall 2018, those with a higher GPA, instate and White are most likely to be admitted by the regular admissions process.

When measuring first to second year retention, once again the researcher ran numerous regressions. In considering college admission test scores, high school GPA, and IR scores the variants of high school GPA and test scores were shown to be significant in predicting first to second year retention rates. This is congruent with 
past research focused on retention (Astin, 1993; Schwartz \& Washington, 2002; Ting, 1998). The Insight Resume score on its own was not statistically significant in predicting first to second year retention. This contradicts some of the literature that was reviewed in chapter two (Tross, Harper, Osher and Kneidinger, 2000; Melancon, 2002; Crede \& Kuncel, 2008). In other words, while some research has explored that non-cognitive variables have a positive influence on retention, this study does not support that conclusion. Given that it is clear that bias in college testing exists (e.g., Walpole, et al., 2005; Fair Test, n.d.) and that equity issues with high school GPA prevails (e.g.,NAEP, 2010), this is a concerning finding if increasing equity is a priority for an institution.

When demographic variables were added to the measurements listed above, the correlations of admission type, residency, race and gender are significant. A linear regression was conducted for test scores, demographic characteristics, and high school GPA to determine which measures reliably predict first to second year retention of firstyear students. With all variables considered, high school GPA, SAT combined test score and admission committee decision were determined to be the most significant predictors of first-to-second year retention. This is supported by previous research in relation to high school grades and college test scores (e.g., Astin, 1993; Schwartz \& Washington, 2002; Ting, 1998). Again, the insight resume used as a stand-alone has no statistical significance and cannot be used to predict first to second year retention on its own. The findings of this study found no positive correlation between the overall Insight Resume score and retention. Therefore, we cannot conclude that the score of a student's Insight Resume would have an influence on their retention. 
The researcher used all variables to run a logistics regression in order to determine the effects of gender, race, residency, admission type, Insight Resume score, high school GPA, and SAT combined score on the likelihood that a first-year student would persist to the second year. Admissions type (admitted by regular process $\mathrm{v}$ committee process) had the greatest influence in predicting first-to-second year retention. This is an interesting outcome because we know who is more likely to be admitted by committee based on this study, and therefore could use this predictive model to identify students that may need extra support upon admission. White, in-state residents are more likely to be admitted by regular admission. BIPOC students, out-of-state students, and students admitted by committee could benefit from targeted programming aimed at supporting them during their first year of college. This will be discussed more in the following section on implications for practice.

The researcher also looked at retention in regards to BIPOC students compared to White students. White students were more likely to be retained. While this information is unfortunately not surprising (e.g., NSC Research Center, 2020), it is a good reminder to consider increased support or proactive interventions could help support BIPOC students who are less likely to be retained. Despite the desire to provide a more inclusive and equitable admissions process through the use of non-cognitive factors, BIPOC students are still left with a negative impact. The admissions process may not be the best or only way to work towards equity and inclusivity in higher education.

By establishing the relationship between admission and retention, intersecting variables can be further examined quantitatively to see what other factors can be studied 
to ensure admission processes are operational, systemic, equitable, and in alignment with institutional mission and goals. Finding correlations between students when they are admitted and attributes that increase their retention can help inform practice. Ultimately, this knowledge can challenge student affairs practitioners to better support students.

Related to this, research results allowed a predictive model to be established.

Chapter Four, Table 19 outlines this predictive model. From this, we can predict resident students admitted by the regular admission process, male-identified, and white are more likely to be retained. This predictive model also explains correlation between increases in Insight Resume score, higher GPA and higher test scores in relation to first-to-second year retention.

\section{Implications for Practice}

This research has multiple implications for practice. First, strengthening institutional support programs or interventions for students that have identified within the predictive model as having lower retention rates could help counteract students not continuing after their first year. This research study found that BIPOC students are less likely to be retained from their first to second year. Additionally, out-of-state students are also less likely to be retained. Knowing this, the university could consider strengthening interventions for these particular demographics. Adding more support programs targeting these particular demographics could increase retention. Working proactively on tailored supports for students that are known to be at-risk of not being retained, like BIPOC and 
out-of-state students, would be a large and potentially expensive undertaking, but could also help increase retention (Banks \& Dohy, 2019; Kirp, 2019).

It was also brought to light that students who are admitted by committee (i.e. entering the university with a GPA under 3.0) are also less likely to be retained. In fact, admissions type was shown to have the highest impact out of all the variables on first to second year retention. This highlights that students who enter college without meeting the basic admissions requirements might benefit from interventions to help boost their academic competency. It may also mean the university might want to take a high-level look at the committee process. Is there any part of the process that might be reconsidered or changed to help students better prepare for matriculation into college? If considering non-cognitive factors in the admission process is not making the impact on increasing diversity in student populations, other options on meeting the needs of underserved students should be considered. The American Council on Education (2021) recommends considering campus climate, addressing basic needs support, increasing programming, and examining pedagogy practices to assess inclusiveness.

Another implication for practice is considering systemic issues within the college admissions process. The world has changed quite a bit since this research began due to the COVID-19 pandemic. We are in the midst of a global pandemic and last year SAT and ACT tests were not even offered disrupting, although controversial measures related to equity, reliable measures of persistence in college. Many colleges were put in the position of making admissions decisions without college admission test scores to consider for enrollment management, budgetary, and economic purposes. COVID-19 
forced many institutions to adopt test-optional admissions practices which were receiving increasing support before COVID-19. It is critical to continue to evaluate the impact of more holistic admissions processes related to student outcomes to accommodate institutional service missions and the current economic realities. Knowing that the Insight Resume alone is not a predictor of college retention, institutions can refine their assessment models to determine how the intersectionality of a student's identity can be used with the Insight Resume score to provide specific support for students. For example, if a student is in multiple categories at-risk for retention (i.e., BIPOC and out-of-state), could individual answers given in the Insight Resume help support staff and/or academic advisors tailor a meaningful intervention? Sharing the information students provide in the Insight Resume beyond admissions staff in order to tailor interventions could be considered.

Additionally, students applying for admission are coming from an educational system of $12+$ years... are there earlier interventions that universities can employ for students before entering university to address disparities in preparation for postsecondary education? There is information that pre-existing academic preparedness upon entry to college is a factor for student academic success and retention (Camara, 2013). If a student is admitted and considered under prepared is there a responsibility to intervene? The university does have a locus of control once a student is admitted and can offer support services. For example, summer bridge programs have been found to be beneficial for BIPOC students, out-of-state students, and academically at-risk students (Cabrera \& Miner, 2013; Bir \& Myrick, 2015). Interventions focused on preparing students for the 
academic challenges and transitional issues to college would be a proactive way to address concerns about retention.

Finally, this research lead to a predictive model for retention to be established. Chapter Four, Table 19 outlines this predictive model. This model illustrates that students admitted by the regular admission process, male-identified, and white are more likely to be retained. This predictive model also explains correlation between increases in Insight Resume score, higher GPA and higher test scores in relation to first-to-second year retention.

An example of this research's applicability to practice is validating the consideration of multiple measures in predicting a student's ability to persist towards a college degree. For example, solely based on the SAT score of TTSU's freshman population, it is possible to predict that a student can increase their chances of retention by $50 \%$ by increasing their combined SAT score by 167 points. But that analysis doesn't take in to account other underlying characteristics. Using the results of the model of this study, when considering race, BIPOC students have a $\sim 2.20 \%$ less likely chance of being retained with a 167-point increase compared to White students. Out of state students are $\sim 10.3 \%$ less likely to be retained than in-state students for improving their SAT score by 167 points. A student who is admitted by committee, non-resident, BIPOC, and female-identified is $\sim 24.90 \%$ less likely to be retained than a regular admit student who is in-state, White, and male-identified when factoring demographic characteristics alone. This model could have an impact if used at an institution beyond admissions. For example, academic advisors could use the predictive model in a 
dashboard format, enter risk factors that a student may have upon admission to determine how high risk they are for retention, then tailor their outreach and intervention to proactively help a student transition to the university.

The logistic regression model of the study is applicable to other institutions that have a similar level of data. The research methodology of this study could be replicated at other institutions to develop a unique model based on the institution's historical enrollment that can be reliably combined with measures such as standardized test scores and high school GPA and alternative non-cognitive measures such as Insight Resume scores. For example, using the study results, it is also possible to predict that a 0.10 increase in GPA increase for a BIPOC student barely increases the chances of being retained $(\sim 0.30 \%)$ compared to the same change for a white student $(\sim 9.70 \%)$ at TTSU. A one-point increase in IR score for a white student also increases their chances of being retained by $\sim 9.40 \%$ compared to a BIPOC student with a one-point increase in IR scores. Results like these also be used to address the disparities in student enrollment even before the admissions process. For example, addressing the importance of SAT test preparation for students that are considering applying for college that have identifying factors that the model show could have a negative impact on retention.

\section{Recommendations for Research}

As an introductory exploratory study, there are many ways to expand this research moving forward. In addition to the total Insight Resume scores, there are eight noncognitive variables in the Insight Resume which are scored individually: positive self- 
concept or confidence; realistic self-appraisal, especially academic; understands and deals with racism; prefers long-range goals to short-term or immediate needs; availability of a strong support person; demonstrated community service; and knowledge acquired in a field. Due to the results of the study, there is potential that Insight Resume subscores could have predictability in student retention. Further study is suggested for purposes of refining the first-to-second year retention model.

Additionally, this data set involved de-identified student data. Therefore, the researcher was not able to track specific data that might have given a deeper picture of impact. For example, the researcher was not able to determine if BIPOC students were retained whether or not they were admitted by committee or regular process without connecting specific students to their experience. More research with a smaller identified data set may be able to explore this topic in depth.

This particular research focused on first to second year retention as a conventional measure, however, one could consider different aspects and measure Insight Resume impact for things such as college GPA, college graduate rates, and other measures of student engagement and success. The study also only focused on first-time freshman which is not representative of the entire college population that includes transfer students, adult learners, and other factors such as part-time students. Further study should be completed to address the intersectionality beyond what has been conventionally known as the 'traditional' student.

Additionally, this study chose particular demographics to measure based on the data set commonly found in institutional research and federal reporting data sets. The 
researcher focused on gender, residency status, race, and legacy status. It begs the question - what other demographics could be considered in relation to non-cognitive variables to predict college retention. An example of a specific area to consider is socioeconomic status. There is a good amount of research on socioeconomic status and college retention (Laskey \& Hetzel, 2010; Tolliver, 2012; Yorke \& Thomas, 2013) but less on the combination of non-cognitive variables and socioeconomic status.

This research took a quantitative look at this issue. A student and their life experiences are much more complicated than numbers in a data set, yet this gives us a good starting point on what other research methods could add more to this finding. While it gives us interesting information to look at the numbers, it does leave out the ability to look more closely at the individual student and what may impact their Insight Resume scores (i.e. past experiences), but also their first to second year retention. A qualitative researcher might be able to take a deeper dive into the "why" behind the information collected in this study for campus strategic planning purposes. Further research on positive and impactful interventions at this particular institution could also put a focus away from this just being an issue for admission and lead to argument for increased funding for interventions that are working. For this, having a more qualitative narrative on why student at-risk do stay could be helpful.

Finally, the research brought to light that admission type (admitted by regular process versus committee) has the highest impact on retention. Knowing this, further research into the process itself might allow the institution to take a deeper dive in 
considering the admissions process. Is admission by committee working for students? Is the current practice setting students up for success?

\section{Summary}

The findings of the study reliably measured the impact of demographic characteristics, standardized test scores, high school GPA, and IR scores and their impact on retention and institutional admissions process. Specifically, demographic variables of gender, race, residency and high school GPA are reliable predictors if students were likely to be admitted by regular process or by an extended admissions process. When looking at predictors of retention, high school GPA and test scores were shown to predict first to second year retention rates.

The Insight Resume score was not statistically significant in predicting first to second year retention as a single measure, but demonstrated some efficacy in combination with other admission metrics and demographic categories. Based on this information, further study should include more exploration into the use of the Insight Resume especially when considering impacts on underrepresented populations.

This research was helpful in developing a predictive model for how demographics and GPA, test scores and insight resume impact retention. This is a basic model that is focused on just the areas on which this research focused. Expanding this model to include more demographics combined with qualitative narrative could be helpful for increasing retention for academically at-risk students. 


\section{References}

Adebayo, B. (2008). Cognitive and Non-Cognitive Factors: Affecting the Academic Performance and Retention of Conditionally Admitted Freshmen. Journal of College Admission, 200, 15-21.

Affirmative action. (n.d.). Retrieved May 8, 2014, from http://www.merriam-webster.com/dictionary/affirmative action

Affirmative Action Timeline (2007). Retrieved May 1, 2014, from http://www.infoplease.com/spot/affirmativetimeline1.html

Allensworth, E. \& Clark, K. (2020, January 28). High School GPAS and ACT scores as predictors of college completion: Examining assumptions about consistency across high schools - Elaine M. Allensworth, Kallie Clark, 2020. SAGE Journals. Retrieved October 21, 2021, from https://journals.sagepub.com/doi/full/10.3102/0013189X20902110.

American Council on Education, (May 2002). Making the Case for Affirmative Action in Higher Education. On the Importance of Diversity in Higher Education. Washington, D.C. American Council on Education.

American Council on Education. (2021, September 10). Student support and success. Higher Education Today. Retrieved October 24, 2021, from https://www.higheredtoday.org/policy-research/student-support-success/. Anderson, D. (2010). Closing the Achievement Gap on Act \& SAT. Retrieved from http://files.eric.ed.gov/fulltext/ED538190.pdf 
Antonio, A. L. (2003, November-December). Diverse student bodies, diverse faculties. Academe, pp. 14-17.

Association of American Medical Colleges (Ed.). (2021). What it's like to participate in multiple mini interviews (mmis). AAMC. Retrieved September 1, 2021, from https://students-residents.aamc.org/applying-medical-school/article/what-itsparticipate-multiple-mini-interviews-mmis/.

Astin, A. W. (1993). What Matters in College? Four Critical Years Revisited. San Francisco: Jossey-Bass.

Austin v. University of Texas. (2013) In Encyclopedia Britannica. Retrieved http://www.britannica.com/EBchecked/topic/1932521/Fisher-v-University-ofTexas-at-Austin

Baker, C.N., \& Robnett, B. (2012). Race, Social Support and College Student Retention: A Case Study. Journal of College Student Development 53(2), 325335. doi:10.1353/csd.2012.0025.

Banks, T., \& Dohy, J. (2019, January 19). Mitigating barriers to persistence: A review of efforts to improve retention and graduation rates for students of color in higher education. Retrieved October 9, 2021, from https:/files.eric.ed.gov/fulltext/EJ1203738.pdf.

Beale, A. (1970) The Evolution of College Admissions Requirements. The National ACAC Journal, 15(3), 20-22. Retrieved from http://files.eric.ed.gov/fulltext/EJ992666.pdf 
Berger, J. B., \& Milem, J. F. (1999). The role of student involvement and perceptions of integration in a causal model of student persistence. Research in higher Education, 40(6), 641-664.

Best, J. W., \& Kahn, J. V. (2003). Research in Education, Boston.

Bir, B., \& Myrick, M. (2015). Summer bridge's effects on college student success - ed. Retrieved October 23, 2021, from https:/files.eric.ed.gov/fulltext/EJ1106091.pdf.

Breland, H. R., Maxey, J., Gernand, R., Cumming, T., \& Trapani, C. (2002). Trends in College Admission 2000: A report of a national survey of undergraduate admission policies, practices, and procedures. ACT, Inc., Association for Institutional Research, The College Board, Educational Testing Service, and National Association for College Admission Counseling.

Brink, S. (2010, January 10). Amid recession, some college admissions policies look at students' wealth. The Washington Post. Retrieved from http://www.washingtonpost.com/

Brown v. Board of Education of Topeka. (2011). In Encyclopedia Britannica. Retrieved from http://www.britannica.com/EBchecked/topic/81780/Brown-v-Board-ofEducation-of-Topeka

Brunner, B., \& Rowen, B. (2006). Affirmative action timeline. Retrieved February, 5, 2007. 
Cabrera, N.L., Miner, D.D., \& Milem, J.F. (2013). Can a summer bridge program impact first-year persistence and performance? A case study of the New Start Summer Program. Research in Higher Education, 54(5),481-498.

Camara, W. (2013). Defining and measuring college and career readiness: A validation framework. Educational Measurement: Issues and Practice, 32(4), 16-27.

Carnevale, A. \& Strohl, J. (2013) Separate and unequal: How higher education reinforces the intergenerational reproduction of white racial privilege. Retrieved from https://cew.georgetown.edu/wpcontent/uploads/2014/11/SeparateUnequal.FR_.pdf

Casement, W. (2001). Percentage plans and college admissions. Academic Questions, $14(4), 8-28$.

Chandler, M. A. (2011). SAT reading scores drop to lowest point in decades. The Washington Post.

Chang, M. J. (1996). Racial diversity in higher education: Does a racially mixed student population affect educational outcomes?

Credé, M., \& Kuncel, N. R. (2008). Study habits, skills, and attitudes: The third pillar supporting collegiate academic performance. Perspectives on Psychological Science, 3(6), 425-453.

Crosnoe, R. \& Muller, C. (2014). Family Socioeconomic Status, Peers, and the Path to College. Social Problems. 61, 602-624. DOI:

http://dx.doi.org/10.1525/sp.2014.12255 
Dillon, S. (2011, December 3). White house pushes for weighing race in admissions. The New York Times. Retrieved from http://www.nytimes.com

Duckworth, A.L., Peterson, C., Matthews, M.D., Kelly, D.R. (2007) Grit: Perseverance and Passion for Long-Term Goals. Journal of Personality and Social Psychology, 2007, Vol. 92, No. 6, 1087-1101 DOI: 10.1037/0022-3514.92.6.108

Fair Test: The National Center for Fair \& Open University Testing. (n.d.). Retrieved from http://www.fairtest.org

Ferrari, J. R., Parker, J. T., \& Ware, C. B. (1992). Academic procrastination: Personality correlates with Myers-Briggs types, self-efficacy, and academic locus of control. Journal of Social Behavior \& Personality.

Fowler, F. C. (2004). Policy studies for educational leaders: An introduction. Upper Saddle River, NJ: Merrill.

Gurin, P., Dey, E. L., Hurtado, S., \& Gurin, G. (2002). Diversity and higher education: Theory and impact on educational outcomes. Harvard Educational Review, 72, $330-366$.

Gratz v. Bollinger. (2011). In Encyclopaedia Britannica. Retrieved from http://www.britannica.com/EBchecked/topic/1513537/Gratz-v-Bollinger

Green, S. B., \& Salkind, N. J. (2017). Using Spss for Windows and Macintosh: Analyzing and understanding data. Pearson. 
Grutter v. Bollinger, (2011). In Encyclopcedia Britannica. Retrieved from http://www.britannica.com/EBchecked/topic/1513537/Gratz-v-Bollinger

Harnisch, T. L. (2020, February). Top 10 higher education state policy issues for 2020. Top 10 Higher Education State Policy Issues for 2020. Retrieved October 10, 2021, from https://www.aascu.org/policy/publications/policymatters/Top102020.pdf.

Henning, E., Van Rensburg, W., \& Smit, B. (2004). Finding your way in qualitative research. Pretoria: Van Schaik.

Holmes, A., Illowsky, B., \& Dean, S. (2021, July 29). 7.0: Introduction to the central limit theorem. Statistics LibreTexts. Retrieved October 14, 2021, from https://stats.libretexts.org/Bookshelves/Applied_Statistics/Book\%3A_Business_St atistics_(OpenStax)/07\%3A_The_Central_Limit_Theorem/7.00\%3A_Introductio n_to_the_Central_Limit_Theorem.

Hossler, D., \& Anderson, D. K. (2005). The Enrollment Management Process. In M. L. Upcraft, J. N. Gardner, \& B. O. Barefoot, Challenging and supporting the firstyear students: A handbook for improving the first year of college (pp. 67-85). San Francisco: Jossey-Bass.

Ishitani, T. T. (2003) A longitudinal approach to assessing attrition behavior among firstgeneration students: Time-varying effects of pre-college characteristics. Research in Higher Education 44(4): 433-449. 
Jamelske, E. (2009). Measuring the impact of a university first-year experience program on student GPA and retention. Higher Education, 57(3), 373-391.

Jaschik, S. (2010, September 13). Momentum for Non-Cognitive Reviews. Retrieved from http:/www.insidehighered.com/news/2010/09/13/ppi

Kaplin, W. A., \& Lee, B. A. (2009). A Legal Guide for Student Affairs Professionals:(Updated and Adapted from The Law of Higher Education. John Wiley \& Sons.

Kirp, D. L. (2019). The college dropout scandal. Oxford University Press.

Kobrin, J. L., Patterson, B. F., Barbuti, S. M., Mattern, K. D., \& Shaw, E. J. (2008). Validity of the SAT for predicting first-year college grade point average.

Lake, P. F. (2011). Foundations of higher education law \& policy: Basic legal rules, concepts, and principles for student affairs. NASPA.

Lohr, S.L(2010), Sampling: Design and Analysis, 2nd ed., Brooks/Cole.

Lutz, S., \& Huitt, W. (2004). Connecting cognitive development and constructivism: Implications from theory for instruction and assessment. Constructivism in the Human Sciences, 9(1), 67-90.

McClelland, M. M., Acock, A. C., Piccinin, A., Rhea, S. A., \& Stallings, M. C. (2013). Relations between preschool attention span-persistence and age 25 educational outcomes. Early Childhood Research Quarterly, 28(2), 314-324. 
McMaster University. (n.d.). Manual for Interviewers MD Program - McMaster University. Interviewer Manual MMI. Retrieved October 18, 2021, from https://mdprogram.mcmaster.ca/docs/default-source/admissions/interviewermanual-mmi_websiteversion.pdf?sfvrsn=4.

Mattson, C. E. (2007). Beyond Admission: Understanding Pre-College Variables and the Success of At-Risk Students. Journal of College Admission, 196, 8-13.

Melancon, J. G. (2002). Reliability, structure, and correlates of learning and study strategies inventory scores. Educational and Psychological Measurement, 62(6), 1020-1027.

Moreno, P. B. (2003). The history of affirmative action law and it's relation to college admissions. Journal of College Admissions, 179. Retrieved from http://www.

Morgan, G. (2006). Images of the organization: Updated edition of the international bestseller. Thousand Oaks, CA: Sage.

Murtaugh, P.A., Burns, L.D. \& Schuster, J. PREDICTING THE RETENTION OF UNIVERSITY STUDENTS. Research in Higher Education 40, 355-371 (1999). https://doi.org/10.1023/A:1018755201899

National Assessment of Educational Progress (2009). America's High School Graduates. Retrieved from http://nces.ed.gov/nationsreportcard/pdf/studies/2011462.pdf National Assessment of Educational Progress (2010). The Nations Report Card. Retrieved from http://nces.ed.gov/nationsreportcard/pdf/main2010/2011468.pdf 
National Conference of State Legislatures (2014). Affirmative Action Overview.

Retrieved from http://www.ncsl.org/research/education/affirmative-actionoverview.aspx

NSC Research Center. (2020, August 27). Persistence \& Retention - 2019. National Student Clearinghouse Research Center. Retrieved October 19, 2021, from https://nscresearchcenter.org/snapshotreport35-first-year-persistence-andretention/.

Noble, J. P., \& Sawyer, R. L. (2004). Is high school GPA better than admission test scores for predicting academic success in college?. College and University, 79(4), 17.

Oregon Public Broadcasting (2014). History of the SAT: A Timeline. Retrieved from http://www.pbs.org/wgbh/pages/frontline/shows/sats/where/timeline.html

Palmer, M., Hayek, J., Hossler, D., Jacob, S. A., Cummings, H., \& Kinzie, J. (2004). Fifty years of college choice: Social, political and institutional influences on the decision-making process.

Pascarella, E. T., Pierson, C. T., Wolniak, G. C., \& Terenzini, P. T. (2004). Firstgeneration college students: Additional evidence on college experiences and outcomes. Journal of Higher Education, 249-284.

Pascarella, E.T., \& Terenzini, P.T. (2005). How college affects students: A third decade of research. San Francisco: Jossey-Bass. 
Pew Research Center (2014) The Rising Cost of Not Going to College. Retrieved from http://www.pewsocialtrends.org/files/2014/02/SDT-higher-ed-FINAL-02-112014.pdf

Pizzolato, J. E. (2003). Developing self-authorship: Exploring the experiences of highrisk college students. Journal of college student development, 44(6), 797-812.

Plessy v. Ferguson. (2011). In Encyclopedia Britannica. Retrieved from http://www.britannica.com/EBchecked/topic/464679/Plessy-v-Ferguson

Reason, R. D. (2009). Student variables that predict retention: Recent research and new developments. Journal of Student Affairs Research and Practice, 46(3), 850-869.

Reid, H. M. (2014). Introduction to statistics: Fundamental Concepts and procedures of data analysis. SAGE.

Ridgell, S. D., \& Lounsbury, J. W. (2004). Predicting academic success: General intelligence," Big Five" personality traits, and work drive. College Student Journal, 38(4), 607.

Ryan, J. (2013) How Getting in to College Became Such a Long, Frenzied, Competitive Process. The Atlantic. Retrived from http://www.theatlantic.com/education/archive/2013/11/how-getting-into-collegebecame-such-a-long-frenzied-competitive-process/281336/

Sackett, P. R., Schmitt, N., Ellingson, J. E., \& Kabin, M. B. (2001). High-stakes testing in employment, credentialing, and higher education: Prospects in a post-affirmative action world. American Psychologist, 56, 302-318. 
Salkind, N. (Ed.). (2012). Multiple regression. Sage Research Methods. Retrieved October 14, 2021, from https://methods.sagepub.com/Reference/encyc-ofresearch-design/n253.xml

Salkind, N. J., \& Frey, B. B. (2000). Statistics for people who (think they) hate statistics. Thousand Oaks, Calif: Sage Publications, Inc.

SAT results - 2019 SAT suite of Assessments Program results - The College Board.

College Board Program Results. (2020, September 9). Retrieved August 1, 2021, from https://reports.collegeboard.org/archive/sat-suite-programresults/2019/class-2019-results.

Schmitt, N., Oswald, F. L., Kim, B. H., Imus, A., Merritt, S., Friede, A., \& Shivpuri, S. (2007). The use of background and ability profiles to predict college student outcomes. Journal of Applied Psychology, 92, 165-179.

Schwartz, R. A., \& Washington, C. M. (2002). Predicting academic performance and retention among African American freshmen men. Journal of Student Affairs Research and Practice, 39(4), 351-367.

Sedlacek, W. (in press). The Case for Adding Noncognitive Variables as Admissions Measures. Retrieved November 27, 2010, from http://williamsedlacek.info/publications

Sedlacek, W. E. (2004). Beyond the Big Test. San Francisco, CA: Jossey-Bass. 
Sedlacek, W. E. (1996). Employing Noncognitive Variables in Admitting Students of Color. New Directions for Student Services, 74, 79-91.

Steele, C. M. (1997). A threat in the air: how stereotypes shape intellectual identity and performance. American psychologist, 52(6), 613.

Sternberg, R. J. (1985). Beyond IQ. London: Cambridge University Press.

Sternberg, R. J. (1986). What would better intelligence tests look like? In Measures in the college admissions process (pp. 146-150). New York: The College Entrance Examination Board.

Sternberg, R. J. (2006). The Rainbow Project: Enhancing the SAT through assessments of analytical, practical, and creative skills. Intelligence, 34, 321-350.

Studley, R. (2003). Inequality, Student Achievement and College Admissions: A Remedy for Underrepresentation. In R. Zwick (ed), Rethinking the SAT: The Future of Standardized Testing in University Admissions. New York; New York.

The Advisory Board Company (2008). The Benefits of Higher Education. Retrieved from https://www.eab.com/ /media/EAB/Research-andInsights/AAF/Custom/2008/01/Benefits-of-Higher-Education.pdf

Ting, S.-M. R. (1997). Estimating academic success in the 1st year of college for specially admitted white students: A model combining cognitive and psychosocial predictors. Journal of college student development, 401-409. 
Ting, S.-M. R., \& Robinson, T. L. (1998). First-year academic success: A prediction combining cognitive and psychosocial variables for Caucasian and African American students. Journal of college student development, 599-610.

Tolliver, A. (2012, November 30). Influence of socioeconomic status on college retention in Metro North Philadelphia. ProQuest LLC. Retrieved October 18, 2021, from https://eric.ed.gov/?id=ED553685.

Tomsho, R. (2009). Adding personality to the college admissions mix. Wall Street Journal.

Tross, S. A., Harper, J. P., Osher, L. W., \& Kneidinger, L. M. (2000). Not just the usual cast of characteristics: Using personality to predict college performance and retention. Journal of College Student Development.

U.S. Census Bureau (2010). Demographic profiles. Retrieved from http://www.census.gov/2010census/data/

U.S. Department of Education, National Center for Education Statistics. (2010). The Condition of Education 2010. Retrieved from http://nces.ed.gov/fastfacts

U.S. Department of Education, National Center for Education Statistics. (2015). Beginning Postsecondary Students. Retrieved from http://nces.ed.gov/surveys/bps/

U.S. Department of Education, National Center for Education Statistics. (2013). Digest of Education Statistics, 2012 (NCES 2014-015), Chapter 3.

U.S. Department of Justice \& U.S. Department of Education (2011). Guidance on the voluntary use of race to achieve diversity in postsecondary education. 
Washington, DC. Retrieved from

http://www2.ed.gov/about/offices/list/ocr/docs/guidance-pse-201111.html

U.S. Department of Education, National Center for Education Statistics. (2010). Paving

the way to postsecondary education: $k-12$ intervention programs for

underrepresented youth. Retrieved from http://nces.ed.gov/pubs2001/

Villalpando, O. (1994, November). Comparing the effects of multiculturalism and

diversity on minority and white students' satisfaction with college. In Annual Meeting of the Association for the Study of Higher Education, Tucson, AZ, ERIC Clearinghouse, ED (Vol. 375721).

Walpole, M., McDonough, P. M., Bauer, C. J., Gibson, C., Kanyi, K., \& Toliver, R. (2005). This Test is Unfair Urban African American and Latino High School Students' Perceptions of Standardized College Admission Tests. Urban Education, 40(3), 321-349.

Yorke, M. \& Thomas, L. (2003). Improving Retention of Students from Lower SocioEconomic Groups. Journal of Higher Education Policy and Management. 25. 6374. $10.1080 / 13600800305737$.

Yu, C. H. D. G. (2007, January 31). A data-mining approach to differentiate predictors of retention. Online Submission. Retrieved October 3, 2021, from https://eric.ed.gov/?id=ED496657. 
Zeegers, P. (2004). Student learning in higher education: A path analysis of academic achievement in science. Higher Education Research \& Development, 23(1), 3556. 


\title{
Appendix: Insight Resume
}

\author{
Insight Resume
}

Tall Tree State University would like to better understand your perspectives, contributions, qualifications, and diverse talents. Please address your experience in each category keeping in mind how you could contribute to the future community of excellence at OSU. Respond to all six questions and limit answers to 100 words per question.

1. Leadership/Group contributions: Describe examples of your leadership experience in which you have significantly influenced others, helped resolve disputes, or contributed to group efforts over time. Consider responsibilities to initiatives taken in or out of school.

2. Knowledge in a field/creativity: Describe any of your special interests and how you have developed knowledge in these areas. Give examples of your creativity: the ability to see alternatives; take diverse perspectives; come up with many, varied, or original ideas; or willingness to try new things.

3. Dealing with adversity: Describe the most significant challenge you have faced and the steps you have taken to address this challenge. Include whether you turned to anyone in facing that challenge, the role that person played, and what you learned about yourself.

4. Community service: Explain what you have done to make your community a better place to live. Give examples of specific projects in which you have been involved over time.

5. Handling systemic challenges: Describe your experience facing or witnessing discrimination. Tell us how you responded and what you learned from those experiences and how they have prepared you to contribute to the OSU community.

6. Goals/task commitment: Articulate the goals you have established for yourself and your efforts to accomplish these. Give at least one specific example that demonstrates your work ethic/diligence. 